\title{
Soma-specific expression and cloning of PSI, a negative regulator of $P$ element pre-mRNA splicing
}

\author{
Christian W. Siebel, ${ }^{1}$ Arie Admon, ${ }^{2,3}$ and Donald C. Rio \\ Department of Molecular and Cell Biology, Division of Genetics and Division of Biochemistry and Molecular Biology; \\ ${ }^{3}$ Howard Hughes Medical Institute, University of California at Berkeley, Berkeley, California 94720 USA
}

PSI is an RNA-binding protein involved in repressing splicing of the P element third intron in Drosophila somatic cell extracts. PSI produced in bacteria restores splicing inhibition to an extract relieved of inhibitory activity, indicating that PSI plays a direct role in somatic inhibition. Sequence analysis of cDNAs encoding PSI reveals three KH RNA-binding domains, a conserved motif also found in the yeast splicing regulator MER1. Notably, PSI is expressed highly in somatic embryonic nuclei but is undetectable in germ-line cells. In contrast, hrp48, another protein implicated in somatic inhibition, is found in the nucleus and cytoplasm of both tissues. The splicing inhibitory properties and soma-specific expression of PSI may be sufficient to explain the germ-line-specific transposition of $P$ elements.

[Key Words: Drosophila; splicing; P element; PSI; RNA-binding protein; tissue specificity]

Received November 15, 1994; revised version accepted December 28, 1994.

Developmental cues often regulate alternative splicing of precursor messenger RNAs (pre-mRNAs) to generate functionally distinct protein isoforms or to switch gene expression on or off (for review, see Green 1991; Maniatis 1991). Among myriad examples, alternative splicing switches a transcriptional activator to a repressor, alters cell adhesion and cell type, and determines somatic sexual differentiation (for review, see Rio 1993). Thus, identifying the regulatory factors that mediate alternative splicing is likely to provide important insights into mechanisms that govern development and differentiation while also illuminating basic splicing mechanisms.

Two general classes of factors appear to affect alternative splicing: (1) ubiquitously expressed splicing factors with activities or expression levels that are modulated to alter splice site selection or splicing efficiency, and (2) developmental or tissue specifically expressed factors that regulate the activities of general splicing factors. Heterogenous nuclear ribonucleoprotein (hnRNP) Al and the SR family of splicing factors are well-characterized members of the first class. The SR protein ASF-SF2 stimulates splicing from proximal $5^{\prime}$ splice sites $(\mathrm{Ge}$ and Manley 1990; Krainer et al. 1990), whereas hnRNP A1 antagonizes this activity and stimulates splicing from distal 5' splice sites (Mayeda and Krainer 1992), suggesting that the balance between these or related factors af-

Present addresses: ${ }^{1}$ Department of Biochemistry and Biophysics, University of California at San Francisco, San Francisco, California 941430448 USA; ${ }^{2}$ Department of Biology, Technion Institute, Haifa 32000 Israel. fects splice site selection (Cáceres et al. 1994). In addition, the different activities and tissue distributions displayed by individual SR proteins may explain some examples of tissue-specific alternative splicing (Zahler et al. 1993).

Genetic analysis of the Drosophila pathway of somatic sex determination has identified a number of sex-specific alternative splicing factors of the second class, and biochemical experiments have begun to elucidate their positive as well as negative mechanisms of action (for review, see Baker 1989; Hodgkin 1989). Female-specific Sex-lethal (Sxl) protein blocks splicing from the non-sexspecific 3' splice site in transformer (tra) pre-mRNA by competing with the essential splicing factor U2AF for binding to the polypyrimidine tract /Valcárcel et al. 1993). Female tra is itself an alternative splicing factor, and together with SR proteins and tra-2, it forms a splicing enhancer complex at specific exon sequences in doublesex $(d s \mathrm{x})$ pre-mRNA that activates splicing from the upstream female-specific $3^{\prime}$ splice site (Tian and Maniatis 1992, 1993). These examples illustrate how cell typespecific alternative splicing factors can interact with general splicing factors to change splicing patterns.

Studies of Drosophila P transposable elements provide a different paradigm for alternative splicing. Fully spliced $P$ element mRNA, which encodes the transposase required for transposition, is produced only in germ-line cells. In somatic cells, the third intron (IVS3) remains unspliced (Laski et al. 1986). Unlike the majority of partially spliced mRNAs which are retained in the nucleus (Chang and Sharp 1989, 1990; Legrain and Ros- 
bash 1989|, somatic P element mRNA is transported to the cytoplasm where it is translated into a repressor of transposition (Robertson and Engels 1989; Misra and Rio 1990). Thus, P elements exploit alternative splicing as an on-off switch to determine whether the transposase or the repressor is produced. A priori, regulation of IVS3 splicing could involve activation in the germ line, inhibition in the soma or a combination of both.

Biochemical complementation experiments indicate that inhibition of IVS3 splicing in somatic cells plays a role in regulating this tissue-specific splicing event (Siebel and Rio 1990). A multiprotein complex bound to a $5^{\prime}$ exon inhibitory element, in part comprised of a pseudo$5^{\prime}$ splice site, appears to mediate somatic inhibition by blocking U1 snRNP binding to the accurate $5^{\prime}$ splice site and stabilizing U1 snRNP binding to an upstream inactive pseudo-5' splice site (Siebel et al. 1992). Mutations in the inhibitory element disrupt binding of the complex (Siebel et al. 1992) and activate IVS3 splicing in vivo (Chain et al. 1991; P. Seshaiah, C.W. Siebel and D. Rio, unpubl.) and in vitro (Tseng et al.1991; Siebel et al. 19921, providing a correlation between the proteins that comprise the complex and the inhibitory activity. Two components of this complex that each specifically bind to the inhibitory element-a $97-\mathrm{kD}$ protein and $50-\mathrm{kD}$ protein, identified as the hnRNP protein hrp48- have been purified and characterized (Siebel et al. 1994). Antibodies against the $97-\mathrm{kD}$ protein activate IVS3 splicing in somatic extracts, indicating that this protein is a necessary component of the inhibitory activity (Sicbel et al. 1994). For this and additional reasons described here, the $97-\mathrm{kD}$ protein is referred to as the $\underline{\mathrm{P}}$ element somatic inhibitor, or PSI.

These in vitro experiments lead to the prediction that at least one component of the inhibitory complex should be active in the soma but inactive in the germ line. This component could be PSI, hrp48 or additional members of the inhibitory activity. Soma-specific activity could be regulated by post-translational modifications or, in the simplest case, at the level of protein expression.

Here we provide direct biochemical evidence that somatic inhibition requires PSI, isolate cDNAs encoding PSI and examine the tissue distribution of PSI and hrp48. Immunoblotting and whole-mount embryo staining experiments revealed that PSI is expressed in the soma but is undetectable in the germ line. These results provide an important link between PSI activity, studied in vitro, and its role in somatic inhibition in vivo. Soma-specific expression of PSI may be sufficient to explain why $P$ element transposition occurs only in the germ line.

\section{Results}

Recombinant PSI restores inhibition of IVS3 splicing

Antibodies against PSI relieve the inhibition of IVS3 splicing observed in Drosophila somatic cell extracts, suggesting that PSI is a necessary component of the inhibitory activity (Siebel et al. 1994). To further test whether somatic inhibition requires PSI, we asked whether another source of antibodies against PSI also relieves inhibition of IVS3 splicing and whether purified recombinant PSI (rPSI) expressed in bacteria restores the inhibitory activity. Antibodies were raised in rabbits against rPSI or in mice against PSI purified from Drosophila (Siebel et al. 1994). Anti-PSI antibodies were affinity purified using immobilized PSI. Antibodies that failed to bind PSI were purified using immobilized antiIgG and served as a control. Drosophila somatic extracts alone (Fig. 1A, lane 11) or supplemented with these control antibodies (Fig. 1A, lane 12) spliced IVS3 very inefficiently. In contrast, and consistent with previous results (Siebel et al. 1994), addition of the mouse anti-PSI antibodies activated IVS3 splicing (Fig. 1 A, lane 8). Likewise, the rabbit anti-PSI antibodies also activated IVS3 splicing (Fig. 1A, lane 4). In both cases, splicing activation depended on the antibody concentration. (Fig. 1A, lanes 1-10). Analysis with a PhosphorImager indicated that the anti-PSI antibodies activated IVS3 splicing 9- to 12-fold. In summary, two unrelated preparations of antiPSI antibodies, each raised against distinct sources of PSI, both significantly activate IVS3 splicing in somatic extracts. Taken together with the observation that these antibodies specifically recognize PSI on immunoblots (Fig. 5; Siebel et al. 1994; data not shown), these results argue strongly that antibody activation of IVS3 splicing reflects a direct role of PSI in the inhibitory activity.

In further support of this conclusion, rPSI restored the inhibitory activity (Fig. 1B). Again, anti-PSI antibody (Fig. 1B, lanes 3,8) activated IVS3 splicing relative to reactions containing antibody buffer (Fig. 1B, lanes 1,7) or control antibody (Fig. 1B, lanes 2,6). Addition of increasing amounts of BSA to the antibody-activated reaction had no significant effects (Fig. 1B, lanes 5,12-14). However, addition of the same or lower amounts of rPSI inhibited IVS3 splicing (Fig. 1B, lanes 4,9-11). Addition of rPSI had no significant effects on splicing of the fushi tarazu (ftz) intron (Fig. $1 \mathrm{Cl}$, demonstrating that these amounts of rPSI do not nonspecifically block splicing.

We have also used this assay to examine IVS3 substrates carrying mutations that partially activate splicing (Siebel et al. 1992). The anti-PSI antibodies further activate splicing of these substrates (data not shown). This result is consistent with the observation that competition with IVS3 5' exon RNA also further activates splicing of these substrates (Siebel et al. 1992; data not shown) and that PSI can bind to the mutant substrates, apparently by recognizing nucleotides outside of the mutant sequence (Siebel et al. 1994).

\section{Isolation of cDNAs encoding the alternative splicing factor PSI}

PSI that had been purified to near homogeneity (Siebel et al. 1994) was separated from the remaining other proteins by gel electrophoresis, electroblotted to PVDF membrane and partially digested with trypsin. Seven peptides were purified and sequenced (Fig. 2). Sequence 

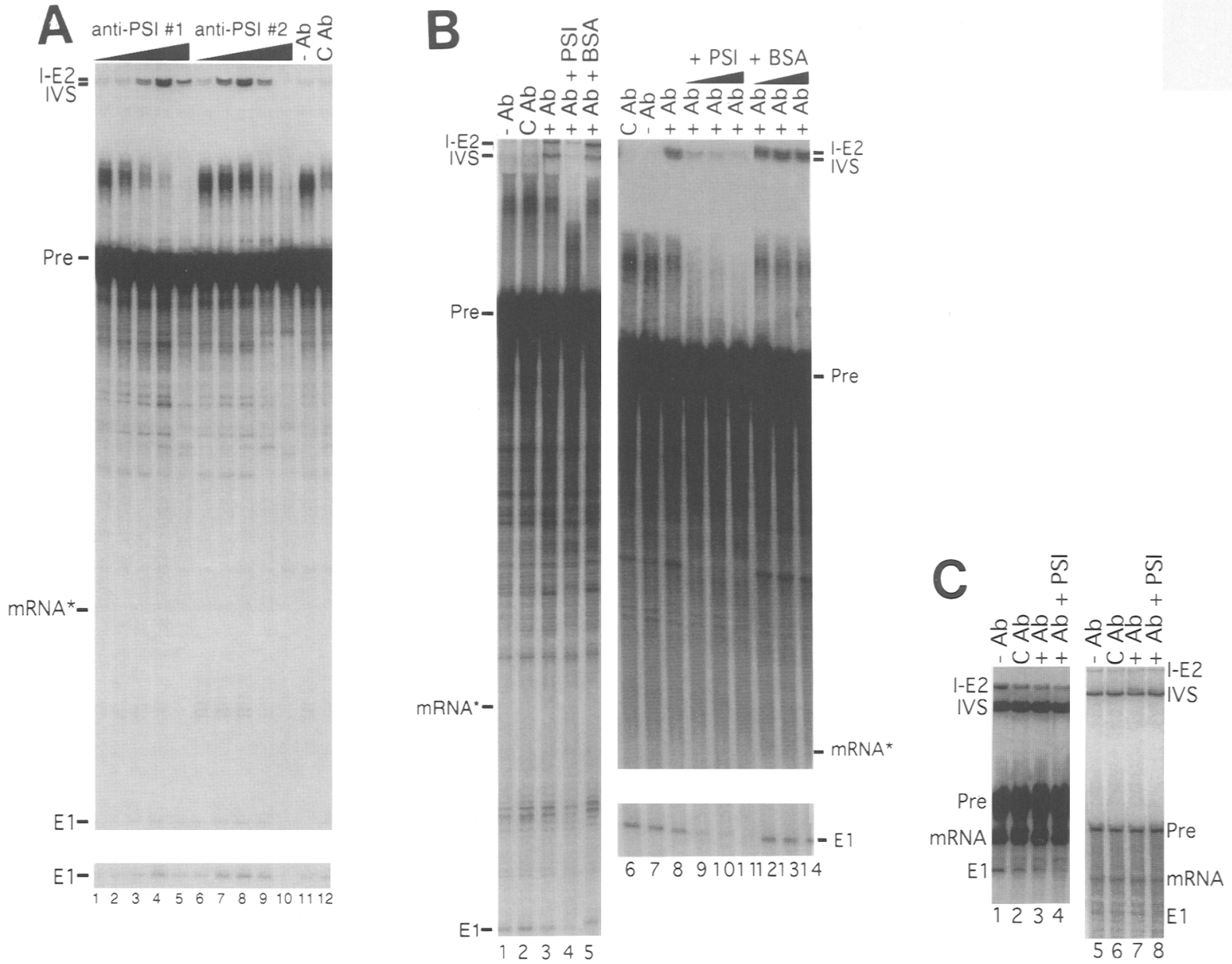

Figure 1. Restoration of IVS3 splicing inhibition by recombinant PSI. (A) Activation of IVS3 splicing in Drosophila somatic extracts by anti-PSI antibodies. The following volumes of affinity-purified antibodies $(0.10-0.13 \mu \mathrm{g} / \mu \mathrm{l})$ raised in rabbits against recombinant PSI (rPSI; lanes 1-5) or in mice against Drosophila PSI (lanes $6-10$ ) were added to in vitro splicing reactions: $0.5 \mu l, 1$ lanes 1,$6 ; 1.0 \mu l$, lanes 2,$7 ; 2.0 \mu \mathrm{l}$, lanes 3,8; $4.0 \mu \mathrm{l}$, lanes 4,$9 ; 7.1 \mu \mathrm{l}$, lanes 5,10. As a control, no antibody (lane 11$)$ or $4 \mu \mathrm{l}(0.13 \mu \mathrm{g} / \mu \mathrm{l})$ of mouse control antibody (lane 12) was added in place of anti-PSI antibody. Different amounts of control antibody failed to activate IVS3 splicing (Siebel et al. 1994). A reaction using human splicing extract (data not shown) was used to mark the positions, noted at left, of the accurate intermediates and products. The lariat intermediate and product migrated close together as a doublet of bands. Cryptic splicing reactions generated additional, previously characterized bands (Siebel et al. 1992). The asterisk denotes that the mRNA product was partially degraded by ribonucleases in the extract and, therefore, was visible only after longer exposures (data not shown). The instability of mRNA products in splicing extracts has been observed previously for IVS3 (Siebel et al. 1992, 1994) and other substrates (Lamond et al. 1987; Barabino et al. 1990; Maschoff and Padgett 1992). (B) rPSI restores inhibition of IVS3 splicing. Rabbit affinitypurified anti-PSI antibody $(4 \mu \mathrm{l}$, lanes $3-5$ and $8-14)$ was added to activate IVS3 splicing reactions as in $(A)$. The same amount of antibody buffer (lanes 1,7) or control antibody (lanes 2,6) served as a control. Where indicated, the following amounts of rPSI or BSA were also added: $1.0 \mu \mathrm{g}$ of rPSI, lane $4 ; 4 \mu \mathrm{g}$ of BSA, lane 5; $0.9 \mu \mathrm{g}, 1.5 \mu \mathrm{g}$, and $3.0 \mu \mathrm{g}$ of rPSI (lanes 9-11) or BSA (lanes 12-14). Lanes 1-5 and 6-14 display the results from two separate experiments. The rPSI preparation is the same as that shown previously (Siebel et al. 1994). (C) ftz splicing. Except for replacing the IVS3 substrate with the $f t z$ substrate, splicing reactions were performed exactly as in $B$. Amounts of $1.0 \mu \mathrm{g}$ and $3.0 \mu \mathrm{g}$ of rPSI were added to the reactions in lanes 4 and 8 , respectively. Lanes $1-4$ and 5-8 display the results from two separate experiments.

information from the amino and carboxyl termini of the longest peptides (such as from amino acids 189-222) was used to design corresponding degenerate oligonucleotides. These oligonucleotides were then used in polymerase chain reactions to amplify portions of the gene encoding PSI from a Drosophila cDNA library. After confirming that the amplified products encoded the correct predicted amino acid sequences, one 800-bp DNA fragment was used to probe a Drosophila cDNA library.
A number of cDNAs were isolated and sequenced (Fig. 2).

In vitro transcription-translation reactions were performed to confirm that the cDNAs encoded PSI. Clone M-1 encoded a $97-\mathrm{kD}$ protein (Fig. 3, lane 1), suggesting that $\mathrm{M}-1$ was a PSI cDNA. This protein translated in vitro comigrated with the faster migrating band in the PSI doublet purified from Drosophila cell extracts (data not shown; Siebel et al. 1994). Thus, post-translational 

1: ATT AAA AAA AAA AAC GTA GAA GCG CAT GAA AAA AAC GGC TCA ACA ATA AGG CAG AGT AGA CAT TCG AAA GCC ACT TAA ACA AAT GCC
88: ATA GGA AGC GTT TAA AAG ATT TCC TCA GCA TTT GTG AAA AAA TCG TCG CTT TCG GCT ATT GAA TTT TCA ACG CGT GCG GTC AAA CAG AAC
178: AAA AAA AAA ACA AGT GGT AAC CAT AAA GAA CCG AAT TGA ACC TAT TAT AAA CCC AGA ACT ATG AGC GAC TTC CAG CAA CAA GGC ATC AAT 178: AAA AAA AAA ACA AGT GGT AAC CAT AAA GAA CCG AAT TGA ACC TAT TAT AAA CCC AGA ACT ATG AGC GAC TTC CAG CAA CAA GGC ATC AAT
1:

268: CAA TCG CAG GCA CTC GCG CAG GCA ATT CAG CGT GCC AAG CAG ATC GCA GCC AAG ATC CAG CCC AGC CAG CAG GGC GGC GGC ACA GCG GGT 11: gln ser gln ala leu ala gln ala ile gln arg ala lys gln ile ala ala lys ile gln pro ser gln gln gly gly gly thr ala gly

358: CCA TCG CCA CCG TCT TCG GGT GGA GGG CCT GGC TTT AAG CGT ATC AAC GAC GAC GGC GAC AGC GGT CCG GAA TCC AAA CGC TCC TTG GGC 41: pro ser pro pro ser ser gly gly gly pro gly phe lys arg ile asn asp asp gly asp ser gly pro glu ser lys arg ser leu aly

448: AGT CCG GAG TAC GCC AAC AAC AGC TCC AAC ATG AGC AGC GGT AGC GGG GGT GGT GGT GGC GGC GGC GGA GGT CCC GGC GGT GCC AGT ATI 71: ser pro olu tyr ala asn asn ser ser asn met ser ser gly ser gly gly gly gly gly gly gly gly gly pro gly gly ala ser ile

538: ACT CAG GCA ATC GCC CAG GCT GCT GCG GTA GCC GCT CGT TTG GCC GCC TCG GCG GGA ACA AGC TGT GAG GAG CAG ATC CGT CTG CCC GAA 101: thr gln ala ile ala gln ala ala ala val ala ala arg leu ala ala ser ala gly thr ser cys glu glu gln ile arg leu pro glu

628: TCG GTA GCC GGC GCC TTT ATG GGT CGC TCC AGT AAC GAC ACC ATC ACC CAC AtC CAG GCC GAG TCC GGT GTA AAA GTG CAG GTC ATG CAG 131: ser val ala gly ala phe met gly arg ser ser asn asp thr ile thr his ile gln ala glu ser gly val lys val gln val met gln

718: GAT CAA GAT CGC GTT ATC ATG TTG CGT GGT CAA AGG GAT ACA GTC ACT AAG GGG CGC GAA ATG ATT CAG AAC ATG GCC AAT CGG GCT GGC 161: asp gln asp arg val ile met leu arg gly gln arg asp thr val thr lys gly arg glu met ile gln asn met ala asn arg ala gly

808: GGG GGA CAG GTG GAG GTG CTG TTG ACG ATC AAT ATG CCG CCA CCG GGA CCT AGC GGG TAT CCA CCT TAC CAG GAG ATC ATG ATT CCG GGC 191: Gly gly oln val glu val leu leu thr ile asn met pro pre profoly pre ser aly tvr pre pre tyr aln alu ile met ile ore aly 898: GCC AAG GTG GGC TTG GTC ATT GGC AAG GGC GGC GAT ACC ATT AAA CAG CTG CAG GAG AAG ACC GGA GCC AAA ATG ATC ATC ATC CAG GAC 221: ala lys val gly leu val ile gly lys gly gly asp thr ile lys gln leu gln glu lys thr gly ala lys met ile ile ile gln asp 98: GGA CCA AAC CAG GAG CTG ATC AAA CCC CTT CGC ATA TCC GGC GAG GCG CAG AAG ATA GAG CAC GCC AAG CAG ATG GTG CTC GAT CTG ATT 251: gly pro asn gln glu leu ile lys pro leu arg ile ser aly aluala alo lys ile alu his ala lys loln met val leu aso leu ile

1078: GCC CAG AAG GAT GCA CAG GGT CAG CAA CAG GGT GGT CGG GGC GGC GGC GGA GGT GGC GGC GGT CCA GGC ATG GGA TTC AAT AAC TTT AAT 281: ala gln lys asp ala gln gly gln gln gln gly gly arg gly gly gly gly gly gly gly gly pro gly met gly phe asn asn phe asn 1168: AAT GGC AAC GGC GGC GAG AGC ACC GAA GTC TTT GTG CCC AAA ATT GCA GTT GGC GTG GTC ATC GGC AAA GGC GGC GAC ATG ATA CGT AAA 311: asn gly asn gly gly glu ser thr glu val phe val pro lys ile ala val gly val val ile gly lys gly gly asp met ile arg lys 1258: ATA CAA ACT GAG TGC GGC TGC AAA CTG CAG TTC ATC CAG GGA AAG AAC GAC GAA ATG GGC GAC CGC AGG TGC GTC ATT CAG GGC ACT CGC 341: ile gln thr glu cys gly cys lys leu gln phe ile gln gly lys asn asp glu met gly asp arg arg cys val ile gln gly thr arg

348: CAG CAG GTC GAC GAT GCC AAg CGC ACC ATT GAT GGG CTA ATT GAA AAC GTT ATG CAA CGA AAT GGC ATG AAT CGA AAT GGC AAT GGA GGA 371: gln gln val asp asp ala lys arg thr ile asp gly leu ile glu asn val met gln arg asn gly met asn arg asn aly asn aly aly

1438: GGC GGT GGC CCA GGA GGA GAC TCT GGC AAC TCC AAC TAC GGC TAT GGG TAC GGC GTA AAT CAC GCT CAA GGT GGA CGG GAG GAA ATT ACA 401: gly gly aly pro aly aly aso ser gly asn ser asp tyr gly tyr gly tyr gly val asn his ala gln gly gly arg glu glu ile thr

1528: TTC CTA GTT CCC GCT TCC AAA TGT GGA ATT GTT ATT GGT CGC GGC GGT GAG ACC ATC AAG CTG ATC AAC CAG CAA TCT GGA GCG CAC ACT 431: phe leu val pro ala ser lys cys gly ile val ile gly arg gly gly glu thr ile lys leu ile asn aln gla ser aly ala his thr 1618: GAA ATG GAT CGC AAT GCC AGC AAT CCC CCC AAC GAG AAG CTC TTC AAA TCT AAG GGC ACC ACC GAC CAG GTG GAG GCT GCC CGC CAA ATG 461 : alu met aso arg asn ala ser asn pro pro asn glu lys leu phe lys ser lys gly thr thr asp gln val glu ala ala arg gln met

1708: ATT TCC GAG AAG ATC AAC ATG GAG CTG AAT GTC ATT TCT CGC AAG CCC ATC GGT GGA GGT CCC GGC GGT GGT GGC GGA AAT TCT GGC GGT 491: ile ser glu lys ile asn met glu leu asn val ile ser arg lys pro ile gly gly gly pro gly gly gly gly gly asn ser gly gly

1798: GGC CAG AAC AAT TCC CAC CAC AAT CAG CAG CAA GGC GGC TAT GGC GGC CAG AAT CAA ATG CAG GGC GGC GAT CCC AAC TCG GGA GCT GGC 521: gly gln asn asn ser his his asn gln gln gln gly gly tyr gly gly gln asn gln met gln gly gly asp pro asn ser gly ala gly 1888: TAC CAA CAA CAG CCT TGG GGT GGA CCC TAC GGG EAG CAG GGT TGG GAT CCG TCC GGT CAA CAG CAG CAA ATG GCC ATG GCT AAT CAA GGG 551: tyr gln gln gln pro trp gly gly pro tyr gly bin gln gly trp asp pro ser gly gln gln gln gln met ala met ala asn gln gly 1978: ГGGC TCT GCT GCG GGA GGA GCT TCC GGT GGT CAA GAC TAC TCG GCT CAG TGG ATC GAG TAC TAC AAA CAA ATG GGA TGC CAT CGT GAG GCT 581 : gly ser ala ala gly gly ala ser gly gly gln asp tyr ser ala gln trp ile glu tyr tyr lys gln met gly cys his arg glu ala 2068: GAA ATG ATC GAG CAG CAA ATG AAG GCC AAA CAG GCG GGC GGC TCC TCC GGT CCT GTC CAG CAG CAA CAA CCC CAA CAG CAG CAA CAG TCC $611:$ glu met ile glu gln gln met lys ala lys gln ala gly gly ser ser gly pro val glnglng gln gln pro glngln gln gln gln fer

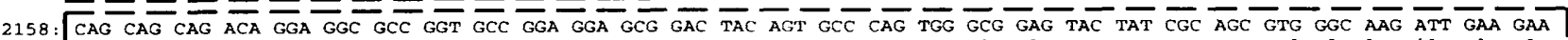
641: gln gln gln thr gly gly ala gly ala gly gly ala asp tyr ser ala gln trp ala glu tyr tyr arg ser val gly lys ile glu glu 2248: GCT GAG GCA ATC GAA AAG ACA TTA AAG AAT AAG CAG AAC GGA TCT GGT GGC CAG AGC AGT ACG CCG AAT CCC AGC CAG GGC GGC TCC GGC 671 : lala glu ala ile glu lys thr leu lys asn lys gln asn gly ser gly gly gln ser ser thr pro asn pro ser gln gly gly ser gly 2338: ICAG CAG CAGlCCC AAT CCC GCT GCG GCG GCG GCG GCA GCA GCT GCT GCT GCA GCG GCG GCC GGT GGT TAT GGC CAG AGC ATG ACG CCC ACT 701 : gin gin ginpro asn pro ala ala ala ala ala ala ala ala ala ala ala ala ala ala gly gly tyr gly gln ser met thr pro thr 2428: CAG TAT GCA CAG TAT TCG CAG TAT TAT GCA GCT GCT GCT GCA GCT GGT GGT CAG CCC CAG GGA GCG CCT CAG CCC GGC GGA GGG CAG AGC 731: gln tyr ala gln tyr ser gln tyr tyr ala ala ala ala ala ala gly gly gln pro gln gly ala pro gln pro gly gly gly gln ser 2518: GGT GGT CCG CCG GGC AAC TAT CCT GGC AAT TAT CCG GGC GCT GGT TAC GGC GGC TAT CCC GGT GCG CCG GGC CAA CAG CAG CAG AAA TCG 761: gly gly pro pro gly asn tyr pro gly asn tyr pro gly ala gly tyr gly gly tyr pro gly ala pro gly gln gln gln gln lys ser 2608: CAC AAA AAC GAC AAT CAC TGA GGA CGT TCG GAT GTA TCG GAA TCG TCG GTA GGg GGA AGg AGg TGT ATG TGG GAG TGG Aag CGA ACG CCG 791: his lys asn asp asn his ***

2698: AAG TGG AAG ATG CTG CGG GTT GAG GAC GAT GCA GGT GCC TTG AAT GGG TGA TCT ATT GTT CTA CTA TGT CCC TAT GTC TTT TAT CCC CCC 2788: ACA AAA CTA GCA AAT CAG AAA TGA AAA GCA AAT GAT TTT TAA TTG CAA TAA CAA CAG CAA AAG CAA AAG CAG AAG CAT CAC CAC CAC CAC 2878: ATA GAC AAC ACA CGG GAT GGA GGC GGA CAT CAG GCG AGG ACC CGG ATA AAT CGG AGA ACG TTA AGC TTT TGC AGA ATT GTA AAT TAA TAC

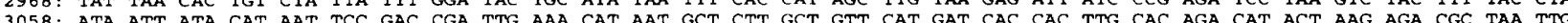
3058: ATA ATT ATA CAT AAT TCC GAC CGA TTG AAA CAT AAT GCT CTT GCT GTT CAT GAT CAC CAC TTG CAC AGA CAT ACT AAG AGA CGC TAA TTG 3148: AAT CCG TTT TGG GTG TTT TGT TCA TTT TTA TAC ACA TCT GCA TAT ATA TAG TCA TAT ATA TAT ATA TAT ATA TAC ATC GCA TAT ATA GGT 3238: TCT TTC ACC GTC AAT TCA GGC AGC CAA TCT GCA ATG GGC GTT CAG TAA TTA AAG ACA CCC TTT GTT AAA ATT CTC AAC TTT AAT GGT AGC 3328: AAT AAA CAA ATC GAA CGT TTT ATA TAC ACG AAC TCA TTT TCA CGT ACT TAG CTT AGC TTA GTT GTA CTA GAA GCC ATT TGA ACT ATA TAT 3418: GAT CGA CAT TTA CAC TTG ATC ATA TAT ACA TAT GTC TGC TGA TCT GGT AAG ATT TAA AAG ATT TGA TCG AAC CTT TTT ATT AAA TTT GAT 3508: TCA AGT GAG GGC CAG GTA CAA AAG GTT ATC TTC CTT AAT TGA TAT TTA ACA TCT TGC ATA ACA ATA TTT TCA TCT TTC AGT TCT GGA GAA 3598: TCT ATG AAA TCA TTT TTG TAG CAC TAA GGT GAA ACT GAA CTG AGT TTA AAA TTA TTT CCT GCT CTA TAA TTG TAT ATT TTT TTA AAT TA 3688: AAA CCT GGT TTG AAT ACG CTT GCA ATA TTT ACC TTT AAA CGA ACG CGC AGG ATA ATC ATG CTT GTT TTA ATA TCT ATT TCA CCA AAT GCA
3778: AAC ATA AAG TAT GTT ATT TTC AGA GGA CGC TCT TCA GAC CAG TTA ATA GCA GAA ATA CGA AAT CAA ACC CCA AAA CTT TTT CAC ACT ATA 3778: AAC ATA AAG TAT GTT

3868: ACA AAT AAC GAA AAC TTG GAA GAG GAA GAA GCG GAA GTG GGC ATT GAT TCG GCT TCT TTT GCC CCA ATC CCC AAA CCA G

Figure 2. (See facing page for legend.) 


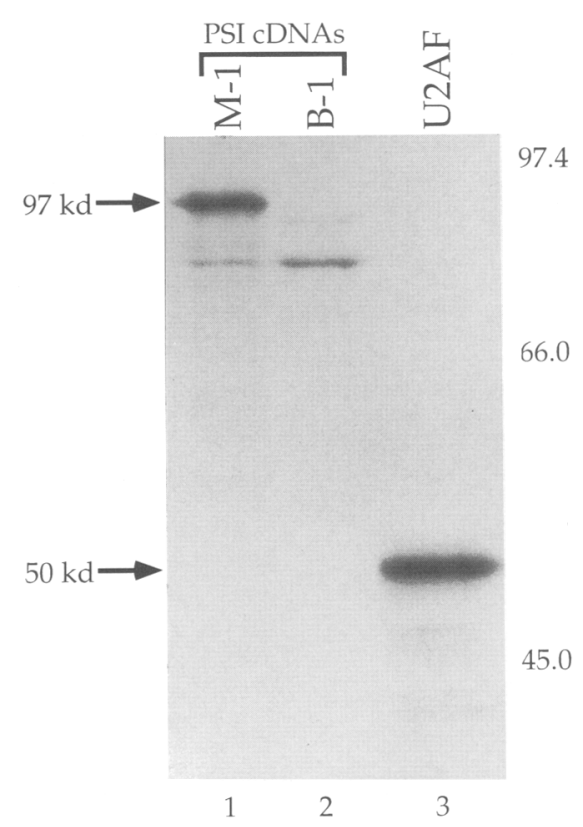

Figure 3. In vitro translation of PSI CDNAs. The PSI M-I (lane 1) and B-1 (lane 2) cDNAs were transcribed with T7 RNA polymerase, translated in vitro in the presence of $\left[{ }^{35} \mathrm{~S} \mid\right.$ methionine, and resolved by electrophoresis through an SDS-10\% polyacrylamide gel. A cDNA encoding the large subunit of Drosophila U2AF (Kanaar et al. 1993) was included as a control (lane 3). The arrows at 97 and $50 \mathrm{kD}$ mark the positions of full-length PSI and U2AF, respectively. The truncated polypeptide of $\sim 75-80 \mathrm{kD}$, visible in lanes 1 and 2, likely results from translation initiation at an internal site.

modifications of the primary translation product may generate the slower-migrating form. DNA sequencing revealed that a second cDNA, B-1, represents a partially spliced mRNA (Fig. 2). A stop codon in the intron of B-1 prevents translation of full-length PSI (Fig. 3, lane 2). The following results further support our conclusion that the cDNAs encode PSI: (1) The predicted amino acid sequence (Fig. 2) contains all seven of the sequenced peptides, (2) like the Drosophila protein (dPSI), rPSI and PSI translated in vitro bind specifically to the IVS $35^{\prime}$ exon (Siebel et al. 1994; data not shown), (3) antibodies against dPSI and affinity-purified by binding to rPSI activate IVS3 splicing in somatic extracts (Siebel et al. 1994), and (4) these same affinity-purified antibodies recognized the dPSI doublet (Fig. 5A).

\section{PSI contains a repeated bipartite RNA-binding domain}

One striking feature of PSI is the presence of three tandem repeats (labeled 1, 2, and 3) of a 100 amino acid domain, in turn, comprised of two subdomains that each bear homology to distinct RNA-binding domains (Fig. 2; Fig. 4A,E). The amino-terminal subdomain conforms to the consensus of the evolutionarily conserved hnRNP K homology $(\mathrm{KH})$ domain found in a large family of RNAbinding proteins (Fig. 4B). PSI joins the yeast meiosisspecific protein MER 1 as the second alternative splicing factor in this family (Fig. 4B). The KH domain is essential for RNA binding of the hnRNP $\mathrm{K}$ and FMR1 proteins (Siomi et al. 1994), suggesting that the PSI KH domains are likely to mediate PSI binding to its target in P element pre-mRNA.

The glycine-rich carboxy-terminal subdomain within the tandem repeats (Fig. 4A) resembles a domain found in a number of nucleic acid-binding proteins including some hnRNPs and nucleolin (Dreyfuss et al. 1993), suggesting that this domain may also play a role in RNA binding. However, the predominance of a single amino acid in this subdomain qualifies the significance of these homologies.

In addition to this subdomain, PSI contains a second distinct glycine-rich domain (Figs. 2 and $4 D, E$ ). This domain of PSI is similar to a carboxy-terminal region of unknown function found in hnRNP $A 1^{\mathrm{B}}$, an alternatively spliced isoform of hnRNP Al (Buvoli et al. 1990).

Finally, PSI contains two repeats, labeled A and B, of a different domain of $\sim 70$ amino acids (Fig. 4D,E). Like the amino-terminal region of PSI, these repeats are rich in glutamine (Fig. 2,4D). The mammalian PSF protein, a splicing factor (Patton et al. 1993), and the mammalian p5 $4^{\text {nrb }}$ protein, an RNA-binding protein thought to function in splicing (Dong et al. 1993), contain similar glutamine-rich domains. The function of repeats $\mathrm{A}$ and $\mathrm{B}$ and the role of glutamine-rich domains in splicing are unknown; however, these regions may mediate proteinprotein interactions (Perutz et al. 1994), as in transcription factor SP1 (Courey and Tjian 1988; Gill et al. 1994).

\section{PSI is expressed in somatic cells but not in germ- line ovary cells}

To examine the tissue distribution of PSI and hrp48, we first performed immunoblotting experiments on nuclear

Figure 2. DNA and predicted amino acid sequence of PSI CDNAs. The cDNA and predicted amino acid sequences of PSI are numbered as shown at left. The three bipartite domains, comprised of the KH RNA-binding domain and a glycine-rich domain, are each boxed with solid lines and the repeated glutamine-rich domains are boxed with broken lines. Amino acids that are overlined and underlined by dashes, respectively, mark regions bearing significant similarity to a carboxy-terminal region of hnRNP A ${ }^{\mathrm{B}}$ and to an asparaginerich domain found in the Drosophila suppressor-of-sable protein (Voelker et al. 1991), a putative regulator of RNA processing (Geyer et al. 1991). Thin-underlined amino acids denote peptide sequences obtained by sequencing purified PSI protein. The arrow shows the location of a 79-nucleotide intron found in the B-1 cDNA. The sequence of this intron, with the $5^{\prime}$ splice site, $3^{\prime}$ splice site, and putative branch point(s) underlined, is shown at the bottom. In situ hybridization maps the PSI gene to 53D 13-15 on the right arm of chromosome 2 (data not shown). 
extracts. We detected high levels of PSI in embryos, which are predominantly comprised of somatic cells, and in somatic tissue culture (Kc) cells (Fig. 5A, lanes 2,8 ). In striking contrast, we detected little or no PSI in a number of different nuclear extracts prepared from handdissected ovaries (Fig. 5A, lanes 3-7). A small amount of PSI was observed in the cytoplasmic fraction of the ovary extracts (Fig. 5A, lane 9). This result may indicate that

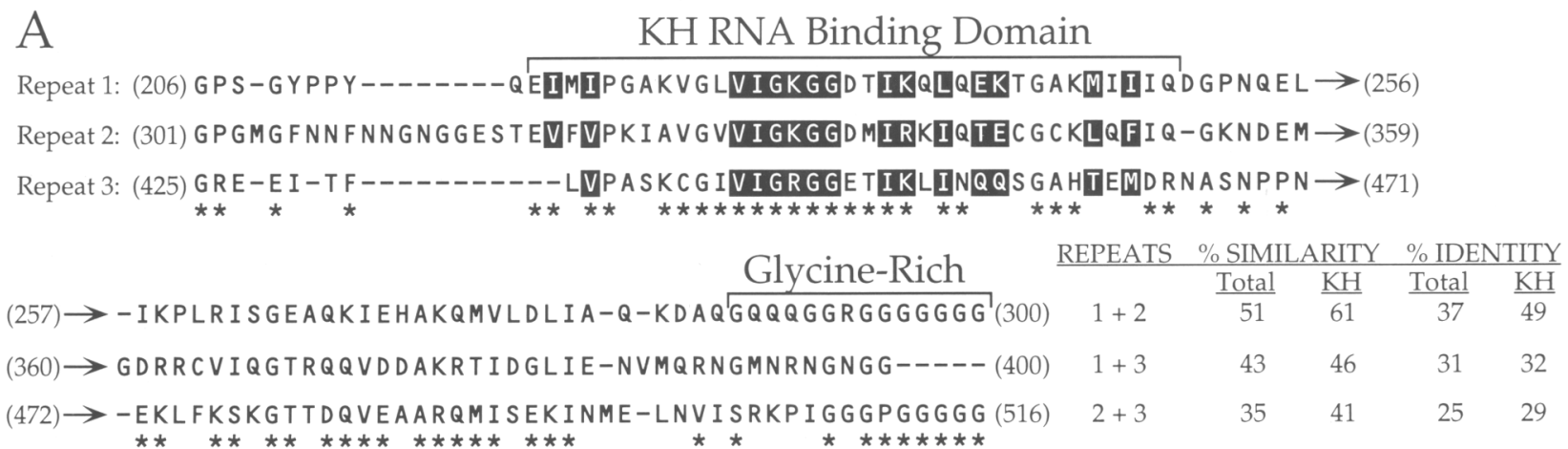

B

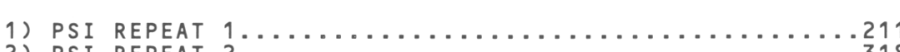

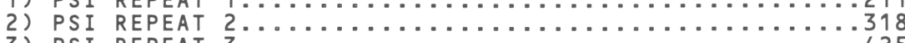

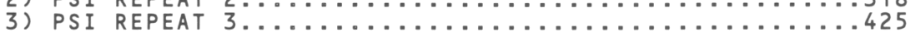

4) POLYRIBONUCLEOTIDE NUCLEOTIDYLTRANSFERASE; E. COLI . 553

5) P62 (GAP-ASSOCIATED; NUCLEIC ACID BINDING); HUMAN . . 173

6) HNRNP COMPLEX K; HUMAN ............................

7) VIGILIN; CHICKEN . . . . . . . . . . . . . . . . . . 583

8) RNP; BRINE SHRIMP . .



10) RIBOSOMAL PROTEIN; MYCOPLASMA-LIKE.............

11) HISTONE-LIKE PROTEIN; YEAST .........................

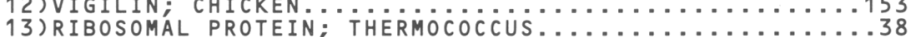

14) RIBOSOMAL PROTEIN; CYANOPHORA $\cdots \cdots \cdots \cdots \cdots$

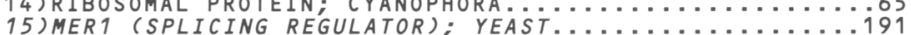





18) NUSA (TRANSCRIPT. TERM, RNA BINDINGi;

19) RIBOSOMAL PROTEIN; THERMOCOCCUS .

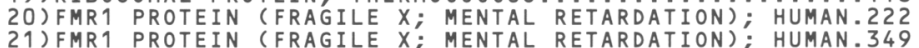

I I GKG GKEI I K I I

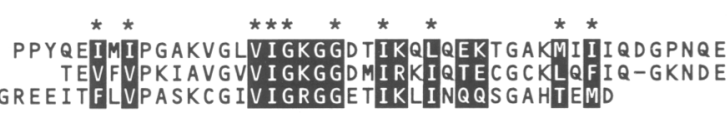

PR I HTIKIN PDKI KDV I GKGGS VI RALTEET GT TIEIEDDG

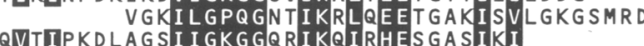

SVPIFKQFHKNI I GKG GANIKKIIREESNTKI I L

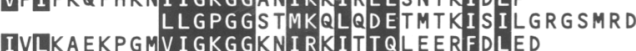

IVLKAEKPGMV I GKG GKN I RKI TT QLEERFDLED

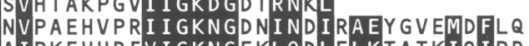

VAIPKEHHR FV I GKNG EKLQDLELKT A TKI QI PR
FVI IKKGEMGLALGKKGANVKRVQNMI GKEIIEVIEHSENPE

LELRTARPGVVVGRGGRGI

FL I GAKG T I ESLREKS G A SIIKIIP

KHTMDIAVEAGNLAQA I GRNGQNVRLA SQLS G
A I GRG GQNINLVKELME

QFIVREDLMGLA I GTHGANIQQARKVPGVT
VIQVPRNLVGKVIGKNGKLIQEIVDKSGVV

CONSENSUS SEQUENCE

I l $\begin{aligned} & 1 \\ & \text { V } \\ & \text { L } \\ & V\end{aligned}$

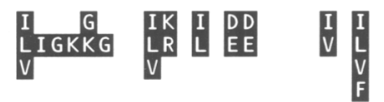

$C$

PSI 508 GGGPGG GG S SGGGQNNSHHNQQQGGYGGQNQMQGGDPNSGAGYQQQPWGGPYG

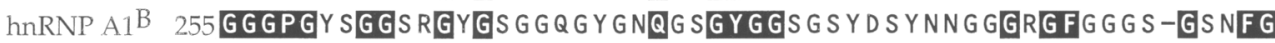

$\mathrm{D}$

PSI Repeat A 570 QQQM AMANQGG SAAGGASGGQDYSAQWIEYYKQMGCHREAEMIEQ QMKAKQ---AGGSSGPVQQQQPQQQQQ PSI Repeat B 641QQQ-.... TGGAGAGGADYSAQWAEYYRS VGK I EEAEAIEKTLKNKQNG SGGQSSTPNPSQGGSGQQQ

$\mathrm{E}$

RNA Binding

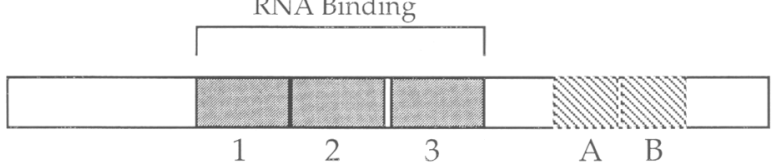

PSI Protein

(796 AA's)

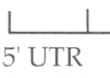

PROTEIN-CODING

$(0.2 \mathrm{~kb})$

$(2.4 \mathrm{~kb})$

3' UTR

PSImRNA

$(3.9 \mathrm{~kb})$

Repeats 1, 2 and 3

(Bipartite repeats $=$ KH RNA binding domain + Gly-rich domain)

Repeats A and B

(Gln-rich)

Figure 4. (See facing page for legend.) 
PSI is excluded from the nucleus of ovary cells. Alternatively, this low level of PSI may reflect expression in the small somatic follicle cell nuclei, which likely remain in solution with the ovary cytoplasm rather than sediment with the larger germ line nuclei /see Materials and methods). In summary, these experiments suggest that PSI is expressed highly in somatic cells but weakly or not at all in germ-line ovary cells.

Unlike PSI, hrp48 was detected at high levels in embryo, $\mathrm{Kc}$, and ovary nuclear extracts (Fig. 5B, lanes 2-7). Thus, hrp48 is expressed in both somatic and germ-line cells. The ovary cytoplasmic fraction contained a moderate amount of hrp48 (Fig. 5B, lane 8).

As a control, the same extracts were electroblotted and probed with antibodies against two other Drosophila proteins involved in RNA metabolism, the poly(A)-binding protein $(\mathrm{PABP})$ and the germ-line-specific vasa protein (Lasko and Ashburner 1990). As expected, PABP was detected in embryo, Kc, and ovary nuclear extracts (Fig. $5 \mathrm{Cl}$. Vasa protein, which has been observed in the nucleus and cytoplasm of only germ-line cells (Lasko and Ashburner 1990), was detected at high levels in nuclear and cytoplasmic fractions of ovaries (Fig. 5D, lanes 1,3). As expected, nuclear extracts from embryos contained a lower level of vasa protein (Fig. 5D, lane 4), and Kc cells contained no detectable vasa protein (Fig. 5D, lane 2). These and other results (Misra et al. 1993) demonstrate that the ovary extracts contain a number of germ-lineexpressed proteins [Fig. 5B-D); thus, the absence of PSI in these extracts likely accurately reflects expression patterns in vivo and strongly suggests that PSI is expressed poorly, if at all, in germ-line ovary cells.

To examine when the genes encoding PSI and hrp48 are transcribed, we performed RNA blot hybridization experiments with poly $(\mathrm{A})^{+}$RNA isolated from ovaries, Kc cells, and from Drosophila at various developmental stages (Fig. 6). A PSI cDNA probe detected a $4.2-\mathrm{kb}$ transcript that was most highly expressed between 2 and $8 \mathrm{hr}$ of embryogenesis and in somatic tissue culture cells (Fig.
$6 \mathrm{~A}$, lanes 3,4,12). Lower levels of this transcript were also observed throughout development (Fig. 6A, lanes 5-11). Notably, ovaries and early embryos expressed only a small amount of the $4.2-\mathrm{kb}$ transcript (Fig. 6A, lanes 1,2). This small amount could result from a low level of PSI transcription in the germ-line or in the somatic ovary follicle cells. Based on its size and expression pattern, this transcript corresponds to the mRNA encoding PSI (Fig. 2). In summary, and consistent with the protein expression results, PSI mRNA was most abundant in somatic cells and at developmental stages where somatic cells constitute most of the organism. However, PSI mRNA may also be present at a low level in the germ line.

The PSI probe also detected two other transcripts. A 6.5- to 7.0-kb transcript, only weakly detected, displayed the same expression pattern as the $4.2-\mathrm{kb}$ transcript (Fig. $6 \mathrm{~A})$. This transcript may represent unprocessed PSI premRNA. Expression of a 2.8-kb transcript was highest in the ovaries and during early embryogenesis (Fig. 6A, lanes 1-3) before decreasing to undetectable levels after 5 hr of embryogenesis (Fig. 6A, lanes 4-10); the ovaries probably contribute the small amount of this transcript that was detected in adult females (Fig. 6A, lane 11). Thus, the $2.8 \mathrm{~kb}$ transcript appeared to be expressed in the germ line and maternally inherited. We do not know whether this transcript encodes a PSI-related protein. However, antibodies against PSI did not detect polypeptides of any size in ovary extracts (Fig. 5A). In DNA blot hybridization experiments, the same PSI probe appeared to detect only a single gene (data not shown); thus, the 2.8- and 7.0-kb transcripts probably arise from the same transcription unit and not from crosshybridization. Moreover, stage-specific differences in the amounts of these transcripts do not simply reflect differences in the amount of RNA loaded per lane because the control actin probe detected approximately equal amounts of actin mRNA in each sample (Fig. 6C).

Probes for hrp48 transcripts also detected two tran-

Figure 4. Repeated domains in PSI and sequence comparisons with other proteins. $(A)$ Sequence alignment of PSI repeats 1, 2, and 3, the bipartite RNA-binding domains. The PSI amino acid numbers are listed at both ends of each line. Positions with similar or identical amino acids in two or three repeats are marked with an asterisk. Both subdomains-the KH RNA-binding domain and the glycine-rich domain-are overlined. The amino acids that comprise the most highly conserved KH positions (Siomi et al. 1993b) are highlighted. The percent similarity and identity for each pairwise comparison of the repeats (total) or the $\mathrm{KH}$ subdomains $(\mathrm{KH})$ are tabulated at the lower right. $(B)$ Sequence alignment of the KH domains in PSI with those from a family of known and putative RNA-binding proteins. The names of the proteins and the positions of the first amino acid in the primary sequence are listed on the left. Asterisks and highlighting mark consensus positions and highly conserved positions, respectively, as defined (Siomi et al. 1993a,b). The sequence of the yeast alternative splicing factor MER 1 is italicized. Sequence alignments were originally generated using the BLAST3 program to search the sequence data bases with the PSI repeats as the query sequences (Altschul et al. 1990). Protein sequences (numbered at left) were obtained from the following references: (1-3) This work; (4) Régnier et al. (1987); (5) Wong et al. (1992); (6) Matunis et al. (1992b); (7) and (12) Schmidt et al. (1992); (8) Cruz-Alvarez and Pellicer (1987); (9) Spiridonova et al. (1989); (10) Lim and Sears (1991); (11) Delahodde et al. (1986); (13 and 19) Klenk et al. (1991); (14) Michalowski et al. (1990); (15) Engebrecht and Roeder (1990); (16) Kroemer et al. (1990); (17) Beckler and Reeve (1986); (18) Saito et al. (1986); (20 and 21) Siomi et al. (1993b). (C) Sequence alignment of PSI amino acids 508-561 and a carboxy-terminal region of mammalian hnRNP Al ${ }^{\mathrm{B}}$. The amino acid positions in the primary sequences are listed at left. Similar and identical amino acids are highlighted. Over this 54 amino acid region, the sequences are $37 \%$ similar and $33 \%$ identical. $(D)$ PSI contains two repeats of a glutamine-rich domain. PSI repeats A and B are aligned as in C. Over this 72 amino acid region, the sequences are $53 \%$ similar and $44 \%$ identical. (E) Schematic diagram of PSI protein and mRNA. The box at the top depicts PSI protein. The three bipartite repeats $(1,2$, and 3$)$ and the two glutamine-rich repeats (A and B) are marked by shaded and cross-hatched boxes, respectively. The line in the center depicts PSI mRNA, which is comprised of untranslated regions (UTRs) and a protein-coding region of the indicated lengths in $\mathrm{kb}$. 


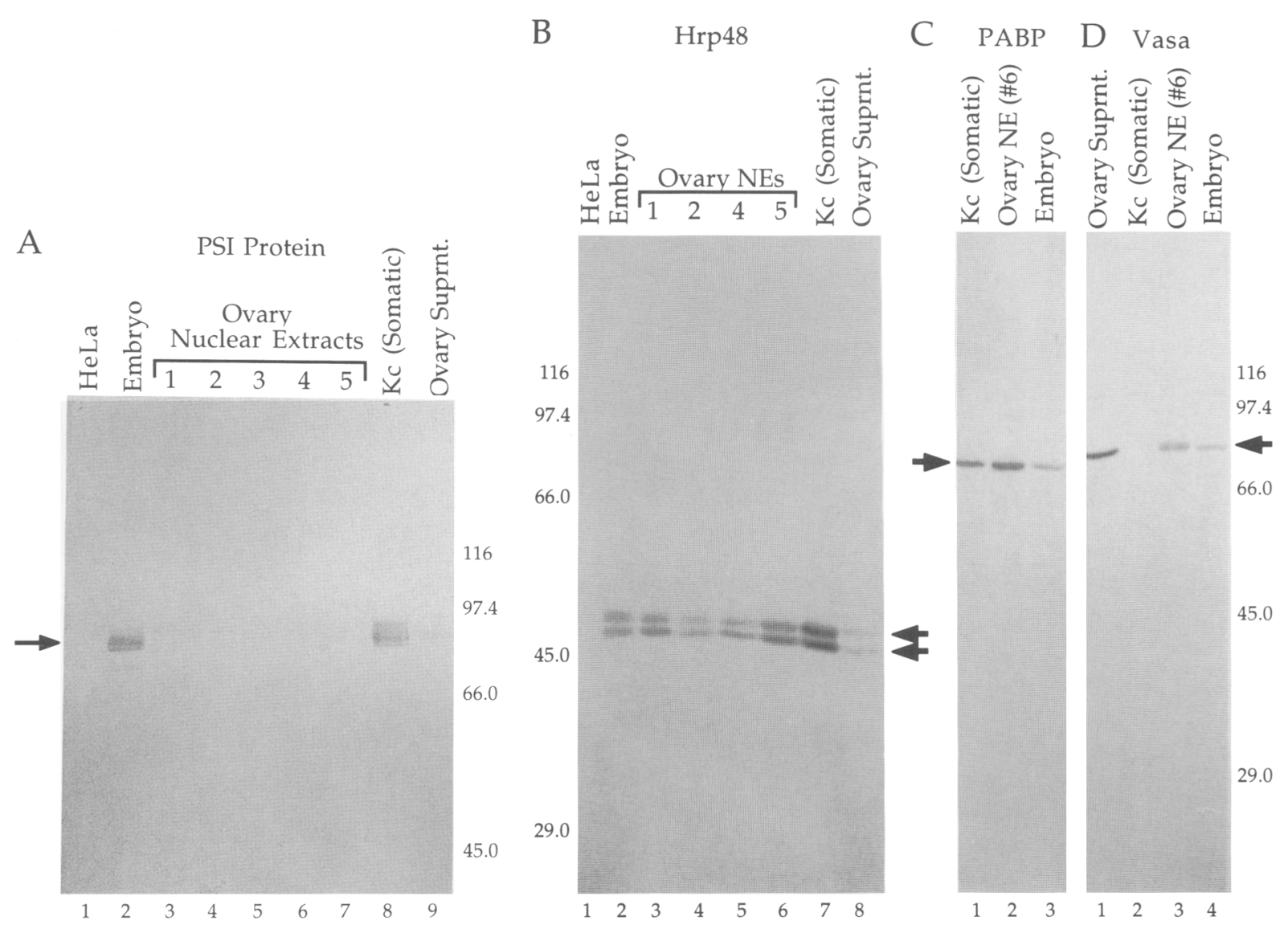

Figure 5. Immunoblots of germ-line and somatic extracts. As noted above each lane, nuclear extracts and the corresponding cytoplasmic supernatants (suprnt.) from different hand-dissected ovaries (batch number listed above each lane) as well as nuclear extracts from somatic Kc tissue culture cells, 0- to 12-hr embryos, and human HeLa tissue culture cells were resolved by electrophoresis through an SDS-8.5\% polyacrylamide gel. The proteins were then transferred to nitrocellulose and probed with the indicated primary antibodies. Immunoreactive proteins were visualized by staining with secondary antibodies coupled to alkaline phosphatase. Both a modified Bradford assay (Pierce) and Coomassie Brilliant Blue staining of gels run in parallel with those shown demonstrated that equal amounts of total protein were loaded in each lane (data not shown). Arrows mark the positions of the immunoreactive proteins. Numbers at the sides mark the mobilities of molecular mass standards in $\mathrm{kD}$. (A) Affinity-purified polyclonal antibodies against PSI. As resolved in this gel, PSI exists in at least two forms that likely differ in post-translational modifications (Siebel et al. 1994). No PSI-related epitopes were detected in human extracts (lane 1). (B) Monoclonal antibody 10D5 against hrp48. hrp48 exists in multiple forms, two of which are resolved in this gel, which are generated by alternative RNA processing or post-translational modifications (Matunis et al. 1992a). This antibody failed to detect a related epitope in human extracts (lane 1). (C) Monoclonal antibody 6E2 against Drosophila PABP. (D) Affinity-purified polyclonal antibodies against the germ-line-specific vasa protein.

scripts (Fig. 6B). Consistent with the protein expression results (Figs. 5 and 7 ), neither transcript appeared to be soma-specific. Expression of the 4.1-kb transcript was highest in ovaries as well as during early embryogenesis (Fig. 6B, lanes 1-4) and continued at a lower level throughout development and in tissue-culture cells (Fig. $6 \mathrm{~B}$, lanes 5-12). Like the maternal PSI transcript of 2.8 $\mathrm{kb}$, a second hrp48 transcript of $2.1 \mathrm{~kb}$ appeared to be expressed maternally because this transcript was detected only in ovaries and during early embryogenesis (lanes 1-4).

\section{Soma-specific expression of PSI during embryogenesis}

To examine PSI expression in situ, we performed wholemount embryo immunostaining using the affinity-puri- fied polyclonal antibodies against PSI and control antibodies described in Figure 1. Antibodies against vasa, a germ-line-specific protein (Lasko and Ashburner 1990), were first used as a control to label the pole cells, the embryonic precursors of the germ line. These antibodies darkly stained the pole cells but not somatic nuclei (Fig. $7 \mathrm{~A}$ ). In contrast, antibodies against PSI strongly stained the somatic nuclei but not pole cells (Fig. 7B). A higher magnification of the posterior pole of the same embryo is shown in Figure $7 \mathrm{C}$. Consistent with the RNA blotting experiments, little or no PSI protein expression was observed before the syncytial blastoderm stage (data not shown|, suggesting that PSI expression begins at this time. Little or no staining was observed when either antibody buffer or the control antibodies were used in place of the anti-PSI antibodies (data not shown). 


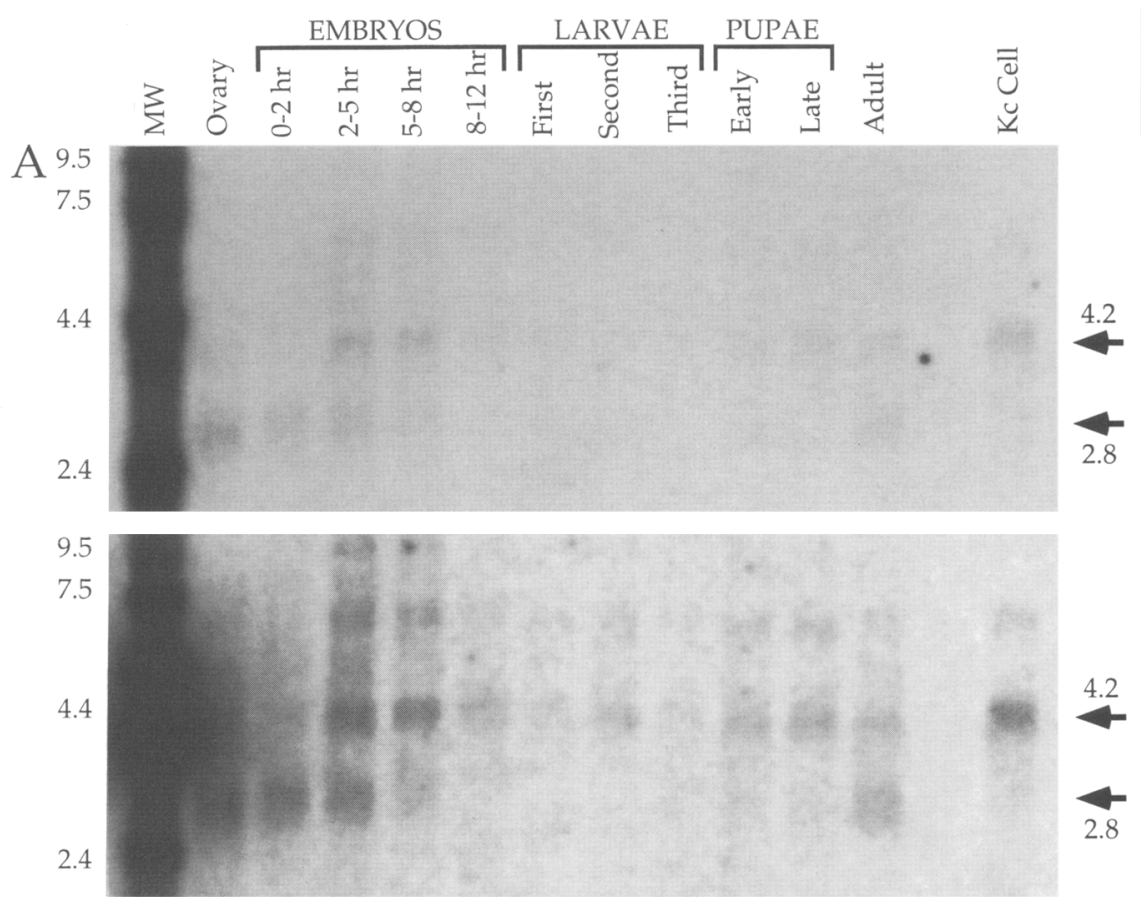

B

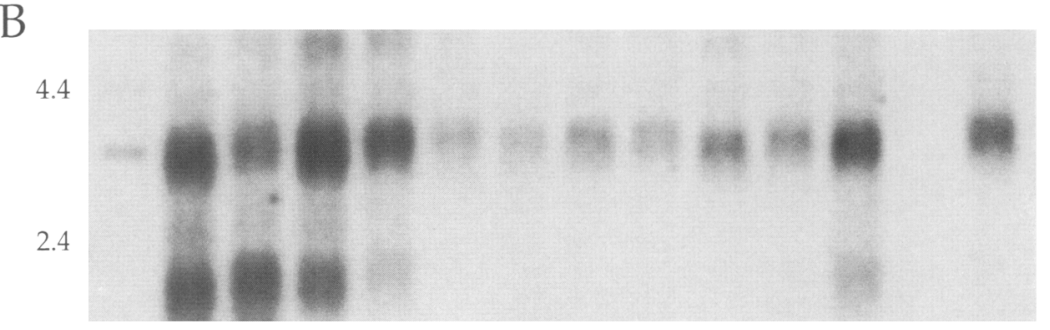

C

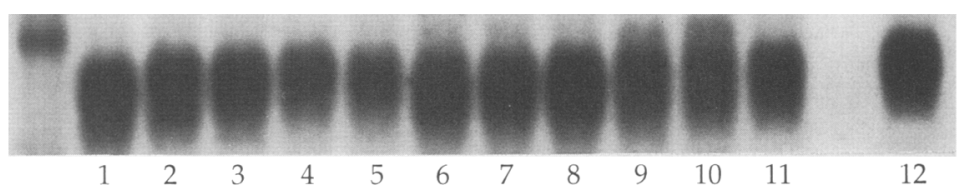

Figure 6. RNA blot hybridizations. Poly $(\mathrm{A})^{+}$RNA from ovaries, Drosophila at different developmental stages, and Kc somatic tissue culture cells was resolved by electrophoresis through a denaturing formaldehyde-agarose gel and transferred to nylon membrane. The blot was then probed with a ${ }^{32} \mathrm{P}$-labeled cDNA fragment. After autoradiography, the probe was stripped off of the blot and the blot was probed with the next cDNA fragment. The lengths (in kb) of the predominant transcripts and RNA size standards (lane 1) are noted at right and left, respectively. (A) PSI cDNA probe. (Bottom) A repeat probing that resulted in a darker exposure of the same blot. $(B)$ hrp48 cDNA probe. (C) Actin 5C cDNA probe.
These observations were extended using simultaneous immunofluorescent staining of the PSI and vasa proteins. Intense vasa expression, indicated by FITC (green) fluorescence, was observed only in the pole cells (Fig. $7 \mathrm{D}, \mathrm{E})$. Strong PSI expression, indicated by rhodamine (red) fluorescence, was observed only in somatic nuclei (Fig. 7E). This rhodamine fluorescence was absent when control primary antibodies replaced the anti-PSI antibodies (Fig. 7D). Colocalization of similar amounts of vasa and PSI would result in a yellow-orange signal. The fact that the green vasa fluorescence in the pole cells appeared identical with control or anti-PSI antibodies (cf. Fig. 7D and E) indicated that PSI is expressed weakly if at all in pole cells. Moreover, little or no rhodamine fluorescence was detected in pole cells when PSI expression was examined alone (data not shown).
Using another assay, immunohistochemical staining with horseradish peroxidase (HRP)-coupled secondary antibody, PSI expression again appeared high in somatic cells but was undetectable in pole cells (Fig. 7F). Because HRP staining quenches fluorescence of the DNA-specific stain DAPI (Steward et al. 1988), somatic cells fluoresced weakly and pole cells fluoresced brightly (Fig. 7G). This result not only confirms that PSI is expressed only in somatic cells, but also demonstrates that PSI is nuclear. As a control, embryos treated in parallel but without anti-PSI antibodies displayed DAPI fluorescence that was equally intense in somatic cells and pole cells (data not shown), confirming that quenching resulted from PSI labeling. This method was also used to confirm that PSI expression was strictly somatic later during embryogenesis after the onset of pole cell migration (data not shown). 
Figure 7. Immunostaining of wholemount embryos. $(A-G)$ Arrows and arrowheads mark the positions of pole cells (embryonic germ-line precursor cells! and somatic cells, respectively. (n) Nucleus; (c) cytoplasm. (A) vasa expression in pole cells. Canton S Drosophila embryos were fixed and incubated with affinity-purified polyclonal antibodies against the germ-line-specific vasa protein. vasa expression was visualized using a secondary antibody coupled to alkaline phosphatase, which stains dark blue. A representative embryo at the blastoderm stage is shown. This plane of focus cuts through the center of the embryo, and thus the somatic nuclei are in focus around the periphery of the embryo. (B) PSI expression in somatic nuclei, not in pole cells. Embryos were treated as in $A$, except that affinity-purified polyclonal antibodies against PSI were used. $(C)$ Higher magnification of the posterior region of the embryo shown in $B .(D, E)$ vasa and PSI double labeling. Embryos were fixed and incubated with the rabbit anti-vasa antibodies together with the mouse control antibodies $(D)$ or the mouse anti-PSI antibodies (E). Localization of the rabbit and mouse primary antibodies was visualized using anti-rabbit secondary antibodies coupled to FITC (green fluorescence) and anti-mouse secondary antibodies coupled to rhodamine (red fluorescence), respectively. To simultaneously see FITC and rhodamine fluorescence, double photographic exposures /one at each fluorescent channel) were taken; both photographs were exposed and processed identically. $(F, G)$ Embryos were stained with the DNA-specific stain DAPI
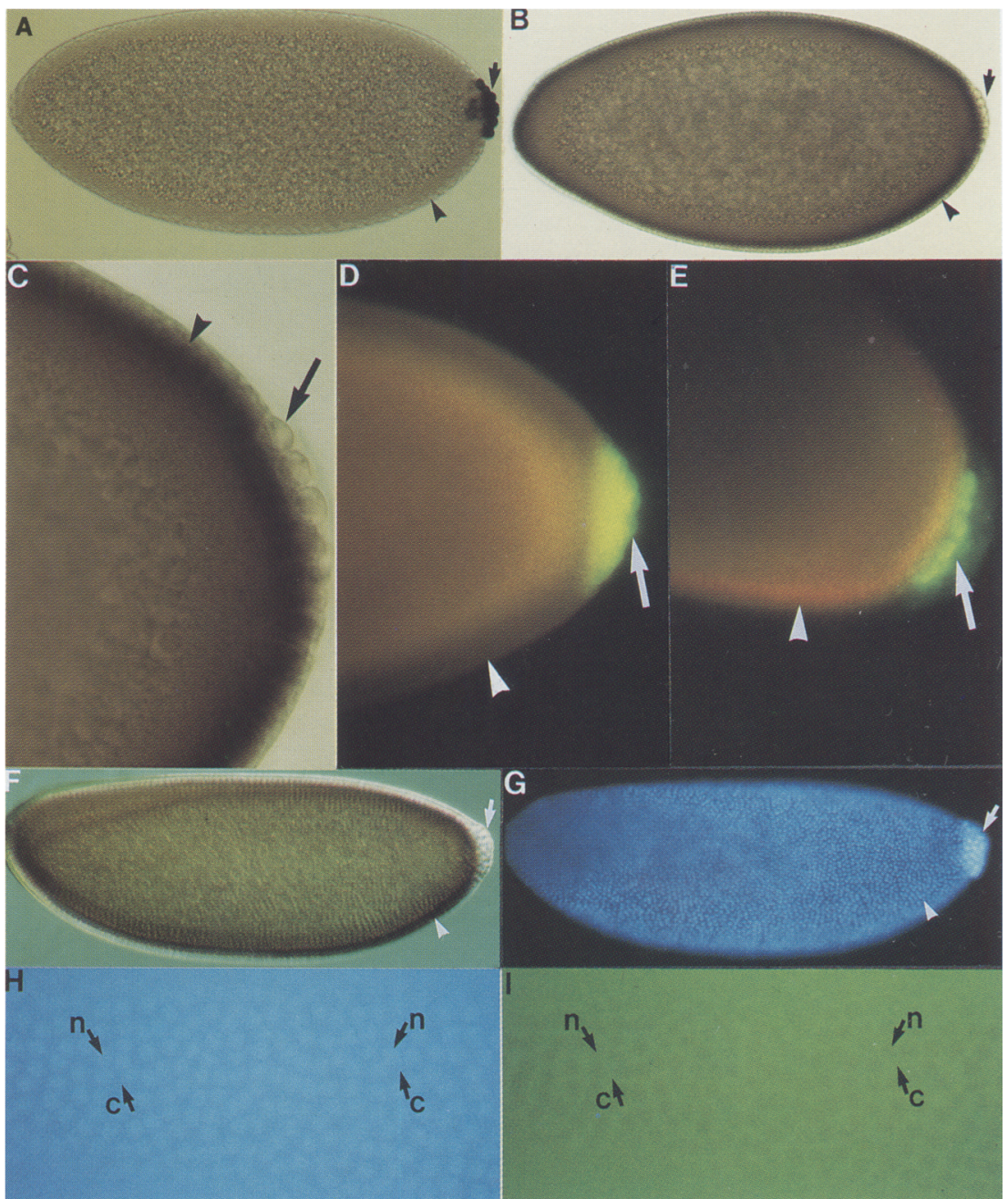

and treated as in $B$ except that the secondary antibody was coupled to HRP. HRP stains dark brown and quenches the blue DAPI fluorescence. $(F)$ HRP staining of a representative embryo at the cellular blastoderm stage. $(G)$ DAPI fluorescence of a second embryo stained in the same way. $(H, I)$ Embryos were stained with DAPI and treated as in $D$ except that the primary antibody was monoclonal antibody 10D5 against hrp48. Similar results were obtained using affinity-purified rabbit polyclonal antibodies against hrp48 (data not shown). $(H)$ DAPI fluorescence at the surface of a representative embryo at the blastoderm stage. (I) hrp48 localization in the same embryo.

\section{hrp48 protein predominantly localizes to the cytoplasm}

Consistent with the protein immunoblot and RNA blot hybridization experiments, whole-mount immunofluorescent staining revealed that hrp48 was expressed in somatic and germ-line cells (data not shown). Surprisingly, hrp48 predominantly localized to the cytoplasm. Figure $7 \mathrm{H}$ displays the surface of a cellular blastoderm embryo stained with DAPI to mark the position of nuclei. Figure 7I displays hrp48 expression of the same embryo viewed by FITC fluorescence; compared with the DAPI-stained view (Fig. $7 \mathrm{H}$ ), the nuclei appear as darkened spots amid intense cytoplasmic hrp48 expression (Fig. 7I). We have consistently observed this pattern throughout early embryogenesis $(0-12 \mathrm{hr}$ after egg depo- sition) using either monoclonal or affinity-purified polyclonal antibodies against hrp48 (data not shown).

\section{Discussion}

Although alternative splicing is an important mechanism to regulate gene expression, few alternative splicing factors have been studied in detail. We have exploited previously the soma-specific inhibition of $\mathrm{P}$ element IVS3 splicing to begin to identify factors that regulate splicing and characterize their mechanisms of action. A strong correlation between specific binding to a $5^{\prime}$ exon inhibitory sequence and inhibition of IVS3 splicing in somatic cell extracts first implicated hrp48 and a $97-\mathrm{kD}$ protein, now designated PSI, as components 
of the inhibitory activity (Siebel and Rio 1990; Siebel et al. 1992). PSI was shown to play a role in the inhibitory activity because antibodies against PSI specifically activate IVS3 splicing in somatic extracts (Siebel et al. 1994). We have now also shown that recombinant PSI restores inhibition of IVS3 splicing to antibody-activated reactions, indicating that the inhibitory activity requires PSI. The simplest of a number of possible models (discussed below) predicts that PSI or hrp48 is a soma-specific regulatory factor.

Here we have presented experiments that test this hypothesis. Immunoblotting and whole-mount embryo staining demonstrate that PSI is highly expressed in somatic nuclei but weakly or not at all in germ-line ovaries and embryonic pole cells. In contrast, hrp48 is expressed in both the soma and germ line. Together with the splicing inhibition results, these expression results suggest that PSI is a soma-specific alternative splicing factor whereas hrp 48 is a generally expressed factor that may be recruited for somatic inhibition.

\section{A soma-specific alternative splicing factor}

The observation that $\mathrm{P}$ element transposition occurs only in the germ line presented an important paradigm for studies of tissue-specific gene expression (Engels 1979). Later results demonstrating that inhibition of IVS3 splicing in somatic cells prevents transposase production reduced this question to one concerning identification of the factor(s) that generate this soma-specific inhibitory activity (Siebel and Rio 1990). A priori, somaspecific activity could be controlled in a number of ways and reside in one or more of a number of factors. For example, activity could be controlled at the level of protein expression. Alternatively, post-translational modifications could alter the activity of a protein expressed in the soma and germ line. Soma specificity could reside in one of the RNA-binding proteins that contacts the inhibitory RNA target sequence in the IVS $35^{\prime}$ exon. These factors include PSI and hrp48, which specifically bind to this inhibitory element, as well as $65-$ and $40-\mathrm{kD}$ proteins that bind with less specificity (Siebel et al. 1992, 1994). On the other hand, soma specificity could reside in a factor that does not directly contact the inhibitory sequence.

We tested the simplest of these models: That one of the proteins that specifically binds to the inhibitory sequence, namely PSI or hrp48, is expressed in the soma but not in the germ line. Whole-mount embryo staining experiments revealed that PSI is (1) easily detectable in somatic cells, (2) localized to the nucleus and, (3) undetectable in pole cells, precursors to the mature germ line. These and the immunoblotting experiments demonstrate that PSI is clearly expressed much more highly in the soma relative to the germ line; therefore, we describe PSI as soma-specific. Our results, however, do not exclude the possibility that PSI is expressed at a low level in the germ line. For example, we have not examined PSI expression during all developmental stages, and thus it is possible that PSI is expressed in the germ line at some time. More importantly, PSI could be expressed below detectable levels in the germ-line tissues we examined. We detected a small amount of the 4.2-kb PSI mRNA in ovaries, although this transcript could be expressed in somatic follicle cells, and only very low levels of PSI protein were detected in ovary nuclear extracts. Consistent with the hypothesis that a low level of PSI exists in the germ line and functions there to inhibit IVS3 splicing in some P element pre-mRNAs, a subfraction of mature P element mRNA in the germ line appears to retain IVS3 (Misra and Rio 1990; Misra et al.1993).

Together with the splicing inhibitory properties of PSI in vitro, soma-specific PSI expression may be sufficient to explain the germ-line specificity of $\mathrm{P}$ element transposition. Factors other than PSI may also be required to restrict transposition to the germ line. For example, the somatic inhibitory activity appears to involve a number of proteins in addition to PSI, and some of these might also be expressed specifically in the soma. Furthermore, the identification of a factor required to inhibit IVS3 splicing in somatic cells does not exclude the possibility that efficient IVS3 splicing in the germ line requires a germ-line-specific splicing activator. Taking advantage of Drosophila genetics, we should be able to test these hypotheses and determine whether PSI plays a general role in differentiating the soma from the germ line.

In contrast to PSI, hrp48 appears to be generally expressed because it was detected in somatic cells as well as ovaries and pole cells. Models explaining the role of hrp48 in somatic inhibition and in relation to PSI have been discussed explicitly (Siebel et al. 1994). Although PSI may be the only soma-specific component of the inhibitory activity, other factors must in turn control the soma-specific expression of PSI. In principle, PSI expression could be controlled at the levels of transcription, splicing, polyadenylation or RNA stability. Given that the expression of some splicing regulators is governed by alternative splicing (for review, see Baker 1989; Ge et al. $1991)$ and that a second smaller PSI transcript was detected in ovaries, an intriguing possibility is that somaspecific PSI expression is itself controlled by alternative splicing.

\section{RNA binding and regulation of splicing}

PSI and the yeast MERl protein are two alternative splicing factors in the $\mathrm{KH}$ family of RNA-binding proteins. Interestingly, both proteins function in similar ways. MER1 activates MER2 by stimulating splicing from the non-consensus 5' splice site in MER2 pre-mRNA (Nandabalan et al. 1993). MER 1 is an RNA-binding protein (K. Nandabalan and G. Roeder, pers. comm.|, and thus this stimulation could be mediated by MERl binding to MER2 pre-mRNA. Only meiotic cells express MER1, and therefore MER2 splicing is meiosis-specific (Engebrecht et al. 1991). PSI functions by binding to the 5' exon of the intron it affects. Moreover, although the net outcome is inhibition rather than activation of splicing, PSI appears to function by stimulating recognition of a nonconsensus, inactive pseudo-5' splice site (Siebel et al. 
1992). Finally, only somatic cells express PSI, and therefore IVS3 splicing is germ line specific. It will be interesting to determine whether MERI and PSI act by similar mechanisms. Such comparisons may help to illuminate conserved mechanisms of alternative splicing as well as $5^{\prime}$ splice site recognition.

Unlike MER 1, which contains one KH RNA-binding domain (Engebrecht and Roeder 1990), PSI contains three. As has been suggested for other splicing factors that contain multiple RNP-CS RNA-binding domains (Zamore et al. 1992; Cáceres and Krainer 1993; Zuo and Manley 1993), three KH domains may increase the affinity or specificity of PSI binding to the inhibitory RNA sequence. Alternatively, if each domain independently recognizes distinct RNA sequences, three domains might allow PSI to recognize different targets. These targets could include pre-mRNAs (such as from the P element/ containing the inhibitory sequence or one of the small nuclear RNAs (snRNAs) required for splicing. In keeping with our model in which the inhibitory activity blocks U1 snRNP binding to the accurate $5^{\prime}$ splice site and stabilizes U1 snRNP binding to an upstream inactive pseudo-5' splice site (Siebel et al. 1992), one RNAbinding domain could bind to the IVS $35^{\prime}$ exon and another to U1 snRNA.

Cytoplasmic localization of hrp48 suggests a possible role in the export of partially spliced P element pre-mRNA from the nucleus to the cytoplasm

hrp48 staining was predominantly cytoplasmic. However, hrp48 must also be present in the nucleus because it has been purified from nuclear extracts (Siebel et al. 1994) and was present in the nuclear fractions from ovaries and $\mathrm{Kc}$ tissue culture cells. Moreover, hrp48 appears to associate with the majority of transcriptionally active chromosomal loci (Matunis et al. 1992a; Matunis et al. 1993). The presence of hrp48 in both the nucleus and cytoplasm suggests that hrp 48 has functions appropriate to both cellular compartments.

One such function could be the export of mRNA from the nucleus to the cytoplasm. Fully spliced P element mRNA in the germ line encodes the transposase protein (Karess and Rubin 1984; Rio et al. 1986). In contrast, partially spliced $P$ element mRNA contains a stop codon within IVS 3 and encodes a truncated protein that represses transposition (Robertson and Engels 1989; Misra and Rio 1990). Interactions with the splicing machinery normally retain such partially spliced pre-mRNAs in the nucleus (Chang and Sharp 1989, 1990; Legrain and Rosbash 1989; Krug 1993), raising the possibility that export of this IVS3-containing $P$ element $m R N A$ may require regulatory factors. Although speculative, the notion that hrp48 facilitates export of partially spliced $P$ element mRNA has precedent. For instance in HIV, following binding to the RRE target sequence, the rev protein appears to disrupt spliceosome assembly and thus increases export of partially spliced HIV mRNAs (Chang and Sharp 1989, 1990; Kjems and Sharp 1993). hrp48 also appears to play a role in inhibiting splicing and binds very specifically to a target immediately adjacent to an unspliced intron (Siebel et al. 1994).

Moreover, hrp48 is a candidate for the functional homolog of mammalian hnRNP Al (Siebel et al. 1994). HnRNP Al shuttles between the nucleus and cytoplasm depending on the transcriptional state of the cell, suggesting that hnRNP Al might function in part as a carrier protein in mRNA export (Piñol-Roma and Dreyfuss 1992). By analogy, hrp48 may function in this way. Existing lethal $\mathrm{P}$ element insertions in the transcriptional control region of the hrp48 gene suggest that hrp48 is essential (R. Kanaar and D. C. Rio, unpubl.) and should permit testing of the putative mRNA export function of hrp48 in vivo.

\section{Materials and methods}

In vitro splicing

In vitro splicing and antibody activation reactions were performed as described (Siebel et al. 1994). The extent of splicing activation was calculated for the lariat product and intermediate using a PhosphorImager (Molecular Dynamics) as described (Siebel et al. 1994). BSA and rPSI were both present in buffer D (Dignam et al. 1983).

\section{Cloning of PSI CDNAS}

PSI purified by RNA affinity chromatography (Siebel et al. 1994) was electroblotted onto polyvinylidene difluoride (PVDF) membrane (Immobilon-P, Millipore) to separate PSI from other proteins. Peptide sequencing form the membrane-bound PSI was performed essentially as described (Williams et al. 1988; Fernandez et al. 1992).

Standard DNA manipulations were performed as described (Sambrook et al. 1989). Degenerate or inosine-containing oligonucleotides were synthesized (Applied Biosystems) that corresponded to the ends of the longest peptides (see Fig. 2). These oligonucleotides were used in touchdown polymerase chain reactions (PCRs) (Don et al. 1991) with DNA prepared from a Drosophila embryo cDNA library (Poole et al. 1985). An 800-bp product (later found to encode amino acids 194-463) was sequenced and found to encode the appropriate peptide sequences. This DNA fragment was ligated to generate tandem repeats and used to probe a Drosophila 4- to 8-hr embryo cDNA library (Brown and Kafatos 1988) essentially as described (Kanaar et al. 1993). Five positive clones, apparently related based on restriction mapping and cross-hybridization (data not shown), were purified to homogeneity. The two longest cDNAs, M-1 and B-1, were completely or partially sequenced, respectively, using Sequenase (U.S. Biochemical).

\section{Protein manipulations}

Coupled in vitro transcription/translation experiments in rabbit reticulocyte lysates were performed according to the manufacturer's specifications (Promega). Immunoblotting was performed essentially as described (Misra and Rio 1990). HeLa and $\mathrm{Kc}$ tissue culture cell extracts, 0 - to $12-\mathrm{hr}$ embryo extracts and nuclear extracts from hand-dissected Drosophila ovaries were prepared as described by Siebel and Rio (1990), Rio (1988), and Misra et al. (1993), respectively. 


\section{RNA blot hybridizations}

These experiments were performed as described (Misra et al. 1993). The first PSI blot was probed with a 3-kb EcoRI-HindIII fragment from the $\mathrm{M}-1 \mathrm{cDNA}$. The second PSI blot was probed with a $0.7-\mathrm{kb}$ M-1 cDNA fragment corresponding to bases 6361354 in Figure 2 . The hrp 48 probe was a PCR fragment containing the complete cDNA sequences (E.L. Matunis, et al. 1992).

\section{Generation of affinity-purified anti-PSI antibodies}

Gel-purified PSI ( $\sim 1-4 \mu \mathrm{g}$ per mouse per injection) was used to generate polyclonal ascites antibodies as described (Karu 1993). Antibodies that specifically recognized PSI were immuno-affinity purified (Harlow and Lane 1988) using recombinant PSI (Siebel et al. 1994) immobilized on Reacti-Gel (Pierce). Antibodies that failed to bind to PSI were immuno-purified using immobilized anti-mouse IgG antibodies (Sigma). Both the anti-PSI and control antibodies were adjusted to a concentration of $0.13 \mathrm{mg} /$ $\mathrm{ml}$. Antibody buffer is $50 \mathrm{~mm}$ glycine, $150 \mathrm{~mm} \mathrm{NaCl}$, and 100 $\mathrm{mM}$ Tris- $\mathrm{HCl}(\mathrm{pH})$.

\section{Embryo staining}

Canton S Drosophila embryos were collected for $13 \mathrm{hr}$ at $25^{\circ} \mathrm{C}$ and fixed immediately (Mitchison and Sedat 1983). For alkaline phosphatase staining, embryos were blocked at room temperature twice for $20-30 \mathrm{~min}$ each in PBST $+15 \%$ goat serum and $0.2 \%$ Tween in PBS (Sambrook et al. 1989) and once for $20 \mathrm{~min}$ in the same solution containing $0.1 \%$ Triton X-100 in place of Tween (PBST $x+1$. Embryos were incubated for $11.5 \mathrm{hr}$ in primary antibody diluted in PBSTx + at $4^{\circ} \mathrm{C}$ and then washed at room temperature three times for $5 \mathrm{~min}$ and four times for 30 min in the same buffer containing $100 \mathrm{mM} \mathrm{NaCl}$ and no goat serum (PBSTxN). These embryos were blocked a second time for $30 \mathrm{~min}$ in PBSTx + . Preabsorbed (to fixed embryos) secondary antibodies (alkaline phosphatase conjugates, Boehringer Mannheim; biotin conjugates, Vectastain; rhodamine and FITC conjugates, Jackson Laboratories) were then incubated with the washed embryos (1:400 dilution) for $1.5 \mathrm{hr}$ at room temperature. The embryos were finally washed in PBSTxN three times for 5 $\mathrm{min}$, twice for $30 \mathrm{~min}$, and twice for $20 \mathrm{~min}$, and developed according to the specifications in the Vectastain substrate kit no. 3 (Vector) before mounting in $70 \%$ glycerol in PBS.

For indirect immunofluorescent staining, embryos were treated in essentially the same way except that PBST + was used and the final washes were for 3 times for $10 \mathrm{~min}$ in PBS containing $0.2 \%$ tween (PBST) and 1 time for $10 \mathrm{~min}$ in PBS. Embryos were mounted in $85 \%$ glycerol and $2.5 \% n$-propyl gallate in PBS.

HRP staining was performed essentially as described (Barker et al. 1992). DNA was stained by incubating the embryos in 1 $\mu \mathrm{g} / \mathrm{ml}$ of DAPI in PBST.

Photomicrographs were taken with a Zeiss Axiophot microscope or with fluorescence or Nomarski optics.

\section{Acknowledgments}

We thank R. Kanaar, H. Madhani, and S. Misra for helpful suggestions on the manuscript. We especially thank T.-M. Yi for his work analyzing the PSI protein sequence, T. Schulman and A. Karu for expert help generating the anti-PSI antibodies, and $T$. Laverty for mapping the PSI gene position on polytene chromosomes. We are grateful to the following people for generously providing a number of reagents: $M$. Adams for the rabbit affinity-purified anti-PSI antibodies; T. Hoey for DNA from the em- bryo cDNA library; R. Kanaar and E. Beall for the U2AF cDNA clone; M. Matunis and G. Dreyfuss for anti-PABP and antihrp48 monoclonal antibodies; S. Misra for the nuclear extracts from hand-dissected ovaries; A. Williamson and S. Roche for the affinity-purified anti-vasa antibodies; and $\mathrm{C}$. Wang for the developmentally staged poly $(A)^{+}$RNA. We also thank K. Nandabalan and G.S. Roeder for communicating results prior to publication. This work was supported by National Institutes of Health grant 5R01-HD28063-04.

The publication costs of this article were defrayed in part by payment of page charges. This article must therefore be hereby marked "advertisement" in accordance with 18 USC section 1734 solely to indicate this fact.

\section{References}

Altschul, S.F. and D J. Lipman. 1990. Protein database searches for multiple alignments. Proc. Natl. Acad. Sci. 87: 55095513.

Baker, B.S. 1989. Sex in flies: The splice of life. Nature 340: 521-524.

Barabino, S.M.L., B.J. Blencowe, U. Ryder, B.S. Sproat, and A.I. Lamond. 1990. Targeted snRNP depletion reveals an additional role for mammalian U1 snRNP in spliceosome assembly. Cell 63: 293-302.

Barker, D.D., C. Wang, J. Moore, L.K. Dickinson, and R. Lehmann. 1992. Pumilio is essential for function but not for distribution of the Drosophila abdominal determinant nanos. Genes \& Dev. 6: 2312-2326

Beckler, G.S. and J.N. Reeve. 1986. Conservation and primary structure in the Hisl gene of the archaebacterium Methanococcus vannielii, the eubacterium Escherichia coli and the cukaryote Saccharomyces cerevisiae. Mol. \& Gen. Genet. 204: 133-140.

Brown, N.H. and F.C. Kafatos. 1988. Functional cDNA libraries from Drosophila embryos. I. Mol. Biol. 203: 425-437.

Buvoli, M., F. Cobianchi, M.G. Bestagno, A. Mangiarotti, M.T. Bassi, G. Biamonti, and S. Riva. 1990. Alternative splicing in the human gene for the core protein Al generates another hnRNP protein. EMBO J. 9: 1229-1235.

Cáceres, J.F. and A.R. Krainer. 1993. Functional analysis of premRNA splicing factor SF2/ASF structural domains. EMBO /. 12: 4715-4726.

Cáceres, J.F., S. Stamm, D.M. Helfman, and A.R. Krainer. 1994. Regulation of alternative splicing in vivo by overexpression of antagonistic splicing factors. Science 265: 1706-1709.

Chain, A.C., S. Zollman, J.C. Tseng, and F A. Laski. 1991. Identification of a cis-acting sequence required for germ linespecific splicing of the P element ORF2-ORF3 intron. Mol. Cell. Biol. 11: 1538-1546.

Chang, D.D. and P.A. Sharp. 1989. Regulation by HIV Rev depends upon recognition of splice sites. Cell 59: 789-795.

- 1990. Messenger RNA transport and HIV rev regulation. Science 249: 614-615.

Courey, A.J. and R. Tiian. 1988. Analysis of $\mathrm{Spl}$ in vivo reveals multiple transcriptional domains, including a novel glutamine-rich activation motif. Cell 55: 887-898.

Cruz-Alvarez, M. and A. Pellicer. 1987. Cloning of full-length complementary DNA for an Artemia salina glycine protein. I. Biol. Chem. 262: 13377-13380.

Delahodde, A., A.M. Becam, L. Perea, and C. Jacq. 1986. A yeast protein $\mathrm{HX}$ has homologies with the histone H2AF expressed in chicken embryo. Nucleic Acids Res. 14: 92139214.

Dignam, J.D., R.M. Lebovitz, and R.G. Roeder. 1983. Accurate 
transcription initiation by RNA polymerase II in a soluble extract from isolated mammalian nuclei. Nucleic Acids Res. 11: 1475-1489.

Don, R.H., P.T. Cox, B.J. Wainwright, K. Baker, and J.S. Mattick. 1991. "Touchdown" PCR to circumvent spurious priming during gene amplification. Nucleic Acids Res. 19: 4008.

Dong, B., D.S. Horowitz, R. Kobayashi, and A.R. Krainer. 1993. Purification and cDNA cloning of HeLa cell p5 $4^{\mathrm{nrb}}$, a nuclear protein with two RNA recognition motifs and extensive homology to human splicing factor PSF and Drosophila NONA/BJ6. Nucleic Acids Res. 21: 4085-4092.

Dreyfuss, G., M.J. Matunis, S. Piñol-Roma, and C.G. Burd. 1993. hnRNP proteins and the biogenesis of mRNA. Annu. Rev. Biochem. 63: 289-321.

Engebrecht, J.A. and G.S. Roeder. 1990. MER1, a yeast gene required for chromosomal pairing and genetic recombination, is induced in meiosis. Mol. Cell. Biol. 10: 2379-2389.

Engebrecht, J.A., K. Voelkel-Meiman, and G.S. Roeder. 1991. Meiosis-specific RNA splicing in yeast. Cell 66: 1257-1268.

Engels, W.R. 1979. Hybrid dysgenesis in Drosophila melanogaster: Rules of inheritance of female sterility. Genet. Res. Camb. 33: 219-236.

Fernandez, J., M. DeMott, D. Atherton, and S.M. Mische. 1992. Internal protein sequence analysis: Enzymatic digestion for less than $10 \mu \mathrm{g}$ of protein bound to polyvinylidene difluoride or nitrocellulose membranes. Analytical Biochem. 201: $255-264$.

Ge, H. and J.L. Manley. 1990. A protein factor, ASF, controls cell-specific alternative splicing of SV40 early pre-mRNA in vitro. Cell 62: 25-34.

Ge, H., P. Zuo, and J.L. Manley. 1991. Primary structure of the human splicing factor ASF reveals similarities with Drosophila regulators. Cell 66: 373-382.

Geyer, P.K., A.J. Chien, V.G. Corces, and M.M. Green. 1991. Mutations in the su(s) gene affect RNA processing in Drosophila melanogaster. Proc. Natl. Acad. Sci. 88: 7116-7120.

Gill, G., E. Pascal, Z.H. Tseng, and R. Tjian. 1994. A glutaminerich hydrophobic patch in transcription factor $\mathrm{Spl}$ contacts the $\mathrm{dTAF}_{\mathrm{II}} 110$ component of the Drosophila TFIID complex and mediates transcriptional activation. Proc. Natl. Acad. Sci. 91: 192-196.

Green, M.R. 1991. Biochemical mechanisms of constitutive and regulated pre-mRNA splicing. Annu. Rev. Cell Biol. 7: 559599.

Harlow, E. and D. Lane 1988. Antibodies: A laboratory manual. Cold Spring Harbor Laboratory, Cold Spring Harbor, New York.

Hodgkin, J. 1989. Drosophila sex determination: A cascade of regulated splicing. Cell 56: 905-906.

Kanaar, R., S.E. Roche, E.L. Beall, M.R. Green, and D.C. Rio. 1993. The conserved pre-mRNA splicing factor U2AF from Drosophila: Requirement for viability. Science 262: 569573.

Karess, R.E. and G.M. Rubin. 1984. Analysis of P transposable element functions in Drosophila. Cell 38: 135-146.

Karu, A.E. 1993. Monoclonal antibodies and their use in measurements of environmental contaminants. In Hazard assessment of chemicals, vol. 8 (ed. J. Saxena), pp. 205-331. Taylor and Francis, Washington, D.C.

Kjems, J. and P.A. Sharp. 1993. The basic domain of rev from human immunodeficiency virus type 1 specifically blocks the entry of U4/U6.U5 small nuclear ribonucleoprotein in spliceosome assembly. I. Virol. 67: 4769-4776.

Klenk, H.P., V. Schwass, and W. Zillig. 1991. Nucleotide sequence of the genes encoding the L30, S12, and S7 equivalent ribosomal proteins from the archaeum Thermococcus celer.
Nucleic Acids Res. 19: 6047.

Krainer, A.R., G.C. Conway, and D. Kozak. 1990. The essential pre-mRNA splicing factor SF2 influences 5' splice site selection by activating proximal sites. Cell 62: 35-42.

Kroemer, W.J., T. Hatakeyama, and M. Kimura. 1990. Nucleotide sequence of Bacillus stearothermophilus ribosomal protein genes: Part of the ribosomal S10 operon. Biol. Chem. Hoppe-Seyler 371: 631-636.

Krug, R.M. 1993. The regulation of mRNA export from nucleus to cytoplasm. Curr. Opin. Cell Biol. 5: 944-949.

Lamond, A.I., M.M. Konarska, and P.A. Sharp. 1987. A mutational analysis of spliceosome assembly: Evidence for splice site collaboration during spliceosome formation. Genes \& Dev. 1: 532-543.

Laski, F.A., D.C. Rio, and G.M. Rubin. 1986. Tissue specificity of Drosophila P element transposition is regulated at the level of mRNA splicing. Cell 44: 7-19.

Lasko, P.F. and M. Ashburner. 1990. Posterior localization of vasa protein correlates with, but is not sufficient for, pole cell development. Genes \& Dev. 4: 905-921.

Legrain, P. and M. Rosbash. 1989. Some cis- and trans-acting mutants for splicing target pre-mRNA to the cytoplasm. Cell 57: 573-583.

Lim, P.-O. and B.B. Sears. 1991. DNA sequence of the ribosomal protein genes rp 12 and rp 19 from a plant-pathogenic mycoplasma-like organism. FEMS Microbiol. Lett. 84: 71-74.

Maniatis, T. 1991 . Mechanisms of alternative pre-mRNA splicing. Science 251: 33-34.

Maschhoff, K.L. and R.A. Padgett. 1992. Phosphorothioate substitution identifies phosphate groups important for premRNA splicing. Nucleic Acids Res. 20: 1949-1957.

Matunis, E.L., M.J. Matunis, and G. Dreyfuss. 1992. Characterization of the major hnRNP proteins from Drosophila melanogaster. 1. Cell Biol. 116: 257-269.

. 1993. Association of individual hnRNP proteins and snRNPs with nascent transcripts. I. Cell Biol. 121: 219-228.

Matuni, M.J., E.L. Matunis, and G. Dreyfuss. 1992a. Isolation of hnRNP complexes from Drosophila melanogaster. I. Cell Biol. 116: 245-255.

Matunis, M.J., W.M. Michael, and G. Dreyfuss. 1992b. Characterization and primary structure of the poly $(\mathrm{C})$-binding heterogeneous nuclear ribonucleoprotein complex $\mathrm{K}$ protein. Mol. Cell Biol. 12: 164-171.

Mayeda, A. and A.R. Krainer. 1992. Regulation of alternative pre-mRNA splicing by hnRNP A1 and splicing factor SF2. Cell 68: 365-375.

Michalowski, C.B., B. Pfanzagl, W. Loeffelhardt, and H.J. Bohnert. 1990. The cyanelle S10 spc ribosomal gene protein gene operon from Cyanophera paradoxa. Mol. \& Gen. Genet. 224: 222-231.

Misra, S. and D.C. Rio. 1990. Cytotype control of Drosophila P element transposition: The $66-\mathrm{kd}$ protein is a repressor of transposase activity. Cell 62: 269-284.

Misra, S., R.M. Buratowski, T. Ohkawa, and D.C. Rio. 1993. Cytotype control of Drosophila melanogaster $P$ element transposition: Genomic position determines maternal repression. Genetics 135: 785-800.

Mitchison, T.J. and J. Sedat. 1983. Localization of antigenic determinants in whole Drosophila embryos. Dev. Biol. 99: $261-264$.

Nandabalan, K., L. Price, and G.S. Roeder. 1993. Mutations in U1 snRNA bypass the requirement for a cell type-specific RNA splicing factor. Cell 73: 407-415.

Patton, J G., E.B. Porro, J. Galceran, P. Tempst, and B. NadalGinard. 1993. Cloning and characterization of PSF, a novel pre-mRNA splicing factor. Genes \& Dev. 7: 393-406. 
Perutz, M.F., T. Johnson, M. Suzuki, and J.T. Finch. 1994. Glutamine repeats as polar zippers: Their possible role in inherited neurodegenerative diseases. Proc. Natl. Acad. Sci. 91: 5355-5358.

Piñol-Roma, S. and G. Dreyfuss. 1992. Shuttling of pre-mRNA binding proteins between nucleus and cytoplasm. Nature 355: 730-732.

Poole, S.J., L.M. Kauvar, B. Drees, and T. Kornberg. 1985. The engrailed locus of Drosophila: Structural analysis of an embryonic transcript. Cell 40: 37-43.

Régnier, P., M. Grunberg-Manago, and C. Portier. 1987. Nucleotide sequence of the pnp gene of Escherichia coli encoding polynucleotide phosphorylase: Homology of the primary structure of the protein with the RNA binding domain of ribosomal protein S1. J. Biol. Chem. 262: 63-68.

Rio, D.C. 1988. Accurate and efficient pre-mRNA splicing in Drosophila cell-free extracts. Proc. Natl. Acad. Sci. 85: 2904-2908.

- 1993. Splicing of pre-mRNA: Mechanism, regulation and role in development. Curr. Opin. Genet. and Dev. 3: 574-584.

Rio, D.C., F.A. Laski, and G.M. Rubin. 1986. Identification and immunochemical analysis of biologically active Drosophila P element transposase. Cell 44: 21-32.

Robertson, H.M. and W.R. Engels. 1989. Modified P elements that mimic the P cytotype in Drosophila melanogaster. $\mathrm{Ge}$ netics 123: 815-824.

Saito, M., A. Tsugawa, K. Egawa, and Y. Nakamura. 1986. Revised sequence of the nusA gene of Escherichia coli and identification of nusA11 $(t s)$ and nusA1 mutations which cause changes in a hydrophobic amino acid cluster. Mol. \& Gen. Genet. 205: 380-382.

Sambrook, J., E.F. Fritsch, and T. Maniatis. 1989. Molecular cloning: A laboratory manual, 2nd ed. Cold Spring Harbor Laboratory Press, Cold Spring Harbor, New York.

Schmidt, C., B. Henkel, E. Poschl, H. Zorbas, W.G. Purschke, T.R. Gloe, and P.K. Müller. 1992. Complete cDNA sequence of chicken vigilin, a novel protein with amplified and evolutionarily conserved domains. Eur. I. Biochem. 206: 625634.

Siebel, C.W. and D.C. Rio. 1990. Regulated splicing of the Drosophila $P$ transposable element third intron in vitro: Somatic repression. Science 248: 1200-1208.

Siebel, C.W., L.D. Fresco, and D.C. Rio. 1992. The mechanism of somatic inhibition: Multiprotein complexes at an exon pseudo-5' splice site control U1 snRNP binding. Genes \& Dev. 6: 1386-1401.

Siebel, C.W., R. Kanaar, and D.C. Rio. 1994. Regulation of tissue-specific $P$ element pre-mRNA splicing requires the RNA-binding protein PSI. Genes \& Dev. 8: 1713-1725.

Siomi, H., M.J. Matunis, W.M. Michael, and G. Dreyfuss 1993a. The pre-mRNA binding protein $\mathrm{K}$ contains a novel evolutionarily conserved motif. Nucleic Acids Res. 21: 11931198.

Siomi, H., M.C. Siomi, R.L. Nussbaum, and G. Dreyfuss 1993 b. The protein product of the fragile $\mathrm{X}$ gene, $F M R 1$, has characteristics of an RNA binding protein. Cell 74: 291-298.

Siomi, H., M. Choi, M.C. Siomi, R.L. Nussbaum, and G. Dreyfuss. 1994. Essential role for KH domains in RNA binding: Impaired RNA binding by a mutation in the $\mathrm{KH}$ domain of FMR1 that causes fragile X syndrome. Cell 77: 33-39.

Spiridonova, V.A., A.S. Akhomanova, V.K. Kagramanova, A.K. Köpke, and A. S. Mankin. 1989. Ribosomal protein gene cluster of Halobacterium halobium: Nucleotide sequence of the genes coding for S3 and L29 equivalent ribosomal proteins. Can. I. Microbiol. 35: 153-159.
Steward, R., S.B. Zussman, L.H. Huang, and P. Schedl. 1988. The dorsal protein is distributed in a gradient in early Drosophila embryos. Cell 55: 487-495.

Tian, M. and T. Maniatis. 1992. Positive control of pre-mRNA splicing in vitro. Science 256: 237-240.

-1993. A splicing enhancer complex controls alternative splicing of doublesex pre-mRNA. Cell 74: 105-114.

Tseng, J.C., S. Zollman, A.C. Chain, and F.A. Laski. 1991. Splicing of the Drosophila P element ORF2-ORF3 intron is inhibited in a human cell extract. Mech. Dev. 35: 65-72.

Valcárcel, J., R. Singh, P.D. Zamore, and M.R. Green. 1993. The protein Sex-lethal antagonizes the splicing factor U2AF to regulate alternative splicing of transformer pre-mRNA. Nature 362: 171-175.

Voelker, R.A., W. Gibson, J.P. Graves, J.F. Sterling, and M.T. Eisenberg. 1991. The Drosophila suppressor of sable gene encodes a polypeptide with regions similar to those of RNAbinding proteins. Mol. Cell. Biol. 11: 894-905.

Williams, T., A. Admon, B. Luscher, and R. Tjian. 1988. Cloning and expression of AP-2, a cell-type specific transcription factor that activates inducible enhancer elements. Genes \& Dev. 2: $1557-1569$.

Wong, G., and O. Müller, R. Clark, L. Conroy, M. Moran, P. Polakis, and F. McCormick. 1992. Molecular cloning and nucleic acid binding properties of the GAP-associated tyrosine phosphoprotein p62. Cell 69: 551-558.

Zahler, A.M., K.M. Neugebauer, W.S. Lane, and M.B. Roth. 1993. Distinct functions of SR proteins in alternative premRNA splicing. Science 260: 219-222.

Zamore, P.D., J.G. Patton, and M.R. Green. 1992. Cloning and domain structure of the mammalian splicing factor U2AF. Nature 355: 609-614.

Zuo, P. and J.L. Manley. 1993. Functional domains of the human splicing factor ASF/SF2. EMBO \% 12: 4727-4737. 


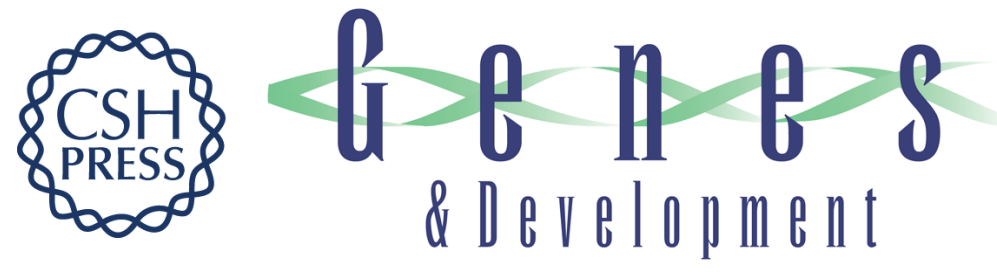

\section{Soma-specific expression and cloning of PSI, a negative regulator of $P$ element pre-mRNA splicing.}

C W Siebel, A Admon and D C Rio

\section{Genes Dev. 1995, 9:}

Access the most recent version at doi:10.1101/gad.9.3.269

References This article cites 82 articles, 29 of which can be accessed free at:

http://genesdev.cshlp.org/content/9/3/269.full.html\#ref-list-1

\section{License}

Email Alerting

Service

Receive free email alerts when new articles cite this article - sign up in the box at the top right corner of the article or click here.

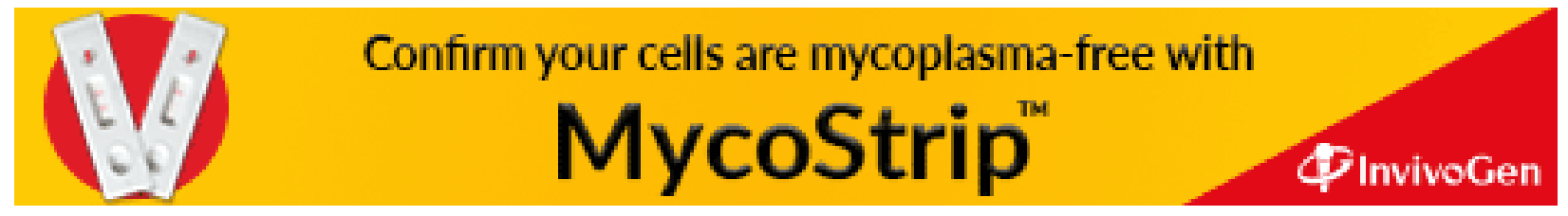

